University of Windsor

Scholarship at UWindsor

4-1-2019

\title{
A review of the use of laser-induced breakdown spectroscopy for bacterial classification, quantification, and identification
}

Steven J. Rehse

University of Windsor

Follow this and additional works at: https://scholar.uwindsor.ca/physicspub

Part of the Physics Commons

\section{Recommended Citation}

Rehse, Steven J.. (2019). A review of the use of laser-induced breakdown spectroscopy for bacterial classification, quantification, and identification. Spectrochimica Acta Part B: Atomic Spectroscopy, 154, 50-69.

https://scholar.uwindsor.ca/physicspub/194

This Article is brought to you for free and open access by the Department of Physics at Scholarship at UWindsor. It has been accepted for inclusion in Physics Publications by an authorized administrator of Scholarship at UWindsor. For more information, please contact scholarship@uwindsor.ca. 
A Review of the Use of Laser-Induced Breakdown Spectroscopy for Bacterial Classification, Quantification, and Identification

Steven J. Rehse

University of Windsor, Department of Physics, Windsor, Ontario, Canada N9B 3P4

\begin{abstract}
The use of laser-induced breakdown spectroscopy to determine the elemental composition of bacterial cells has been described in the peer-reviewed literature since 2003. Fifteen years on, significant accomplishments have been reported that have served to clarify and underscore the areas of bacteriological investigation that LIBS is well-suited for as well as the challenges that yet remain to be faced. This review will attempt to summarize the state of the field by surveying the available body of knowledge. The early days of these experiments, roughly from 2003 to 2007, in which many of the most fundamental experiments were initially conducted will be described. The more in-depth investigations that followed in the subsequent decade will then be detailed. Many important aspects of performing LIBS on bacterial cells were reported on and are summarized here including: the use of chemometric algorithms for statistical classification of unknown spectra; the influence of the mounting substrate on classification; the effect of the testing gas atmosphere and the choice of bacterial cell growth nutrient medium on the measured LIBS spectrum; the efficacy of a LIBS-based test as a genus-level or strainlevel discrimination test; the ability of LIBS to determine the cell titer or concentration of cells in the initial sample; the effects that possible contaminations or interferents within the sample would have on the LIBS spectrum; the influence that environmental stresses the cells may be exposed to during growth and the state of reproductive health of the cells could have on the LIBS spectrum; the use of standoff or remote apparatus to minimize the risk to the operators during bacteriological identification of unknown specimens; and the combination of other optical modalities with LIBS to enhance the sensitivity or specificity of identification. Lastly, tables are provided which summarize both every species of bacteria ever tested with LIBS as well as the major lessons learned by the community through 15 years of careful investigation.
\end{abstract}

laser-induced breakdown spectroscopy; pathogens; bacteria 


\section{Introduction}

\subsection{Overview}

The use of laser-induced breakdown spectroscopy (LIBS) as a powerful and flexible analytic tool for the rapid analysis and characterization of a specimen's elemental composition has been investigated and reported on by a growing international community for approximately the last thirty years. The results of these investigations have been widely published and disseminated and their broad conclusions have been summarized in a string of excellent monographs $[1,2,3,4]$ and review articles $[5,6,7,8,9]$ which have endeavored to advance the overall knowledge of the field.

As described in detail in the above-referenced monographs and articles, LIBS is a laser-based spectroscopic technique that is utilized most frequently to perform rapid elemental analysis on a variety of targets of interest. Briefly, in a typical LIBS experiment a pulse of laser light (usually a nanosecond, picosecond, or femtosecond duration pulse) is focused onto or into a target material which may be a solid, liquid, or gas. The laser pulse ablates micrograms of mass which serve as a sample of the analyte material and it also creates a high-temperature micro-plasma which serves as a thermal excitation source for the ablated sample. The thermodynamics and physics of the breakdown process are different for nanosecond and femtosecond pulses, but the end result is a plasma with an elemental composition that is reflective of the composition of the target material that can be used as an emission source for time-resolved optical emission spectroscopy. This plasma emits light in part due to the spontaneous emission of thermally excited atoms and ions. When dispersed in a spectrometer and detected by a suitable detector, the light from the plasma may be used to qualitatively identify the elemental composition of the original target or quantify the mass or concentration of trace elements in the target.

As the number of researchers and research areas has grown, review articles have been published to effectively collate the knowledge gained from experimentation in specific area of investigations such as the use of LIBS for explosive detection [10], soil analysis [11], nuclear fusion technology [12], plant analysis [13], food analysis [14], archaeological science [15], geochemical and environmental analysis [16], and cultural heritage and space applications [17].

Of particular importance to our group has been the investigation of the applicability and utility of LIBS in medical science, particularly as a pathology/histology laboratory tool or as a rapid point-of-contact assessment diagnostic. This topic, which is sometimes broadly classified into the area of "biomedical applications," has also received significant attention and has been summarized and reviewed in numerous outlets $[18,19,20,21,22]$.

The focus of our group's work has been specifically the use of LIBS for rapid pathogen identification and classification, and even more specifically the analysis of bacterial LIBS spectra (as opposed to the other infectious pathogens such as viruses and fungi) for diagnostic, biochemical, and bioanalytical applications. The aim of this review is to summarize the current progress and understanding in this narrow, yet highly important, sub-field of biomedical applications.

\subsection{Scope}

The potential impact of a new LIBS-based rapid bacterial pathogen detection and identification technology is extremely broad, global in scale, and encompasses several scientific/health communities. Pathogen detection is of the utmost importance for health and safety reasons. According to a 2007 study, three areas of application account for over two thirds of all research in the field of pathogen 
detection: the food industry, water and environment quality control, and clinical diagnosis [23], while military-biodefense constitutes a small niche market for this technology.

Because of the global demand for pathogen detection technology and testing, it was recently reported that the pathogen-specific testing market was expected to grow at a compounded annual growth rate of $4.5 \%$ with a total market value of $\$ 563$ million [24]. The world biosensor market was evaluated at $\$ 7.3$ billion in 2003 and was expected to reach over $\$ 10$ billion with the medical/health area being the largest sector [25].

Seventy-six million foodborne illnesses occur each year in the US and account for 325,000 hospitalizations and 5000 deaths [26]. The United States Department of Agriculture estimates \$2.9-\$6.7 billion will be lost annually due to medical costs and lost productivity caused by major food pathogens [24]. Although significant progress continues to be made, the detection and identification of foodborne pathogens in this sector continue to rely on conventional culturing techniques which are very elaborate, time-consuming, and expensive. The existing test methods are completed in a microbiology laboratory and are not suitable for on-site monitoring. Pathogen detection using existing methods, such as enzyme linked immunosorbent assays (ELISA) and culture techniques for determining and quantifying pathogens in food have been well established [27]. In terms of speed, these methods cannot adequately serve the needs of food processors and regulatory agencies. As a result, the food industry needs real time, portable pathogen detection sensors with higher sensitivity. Rapid detection biosensors will minimize the need for the estimated 60,000 US based food processors to perform lengthy microbial testing and expensive immunoassays on materials suspected of carrying foodborne pathogens [24].

Hospitals typically use their own laboratory for identifying bacterial pathogens. A urine, sputum, or blood sample is sent to the laboratory and tests are performed to determine if a pathogen is present. Testing requires $24 \mathrm{~h}$ (typically) and with laboratory back-ups, results can take up to days. The addition of the LIBS technology to diagnostic labs could minimize the suffering of patients, improve outcomes, and reduce hospital admissions and associated expenses by allowing the initiation of appropriate therapy based on immediate or "point-of-contact" diagnosis. Beyond mere bacterial identification, LIBSbased bacterial diagnostic/sensing technology could enable a variety of microbiological research of interest to both the diagnostician and the research microbiologist. Several examples of such applications will be provided here.

\subsection{Non-bacterial pathogens}

The potential impact of a real-time LIBS diagnostic tool capable of sensitive and specific pathogen identification is clear. Although this review will focus exclusively on bacterial pathogens, the use of LIBS for identifying other microbes or pathogens has also been reported, particularly when those nonpathogenic microbes could confuse the results of a test for more harmful microorganisms. Such microbes, or any other such material, can be classified as "confusants" or "interferents": small or microscopic materials that can obscure the pathogen signature in the LIBS spectrum. Their analysis for this reason, as well as their own intrinsic infectious capability, is warranted. And while these organisms are outside the scope of this review, because they are often reported in studies with bacterial pathogens a quick summary of the work is provided here.

Pollen spores occur ubiquitously in nature, particularly in outdoor environments, where they act as interferents for technologies designed to detect harmful bioagents such as Bacillus anthracis ( $B$. anthracis) spores (responsible for anthrax). Their presence in medical specimens is unexpected. Early studies indicated a clear ability to reliably differentiate the LIBS spectrum of such naturally occurring 
pollen (e.g. oak pollen, ragweed pollen) from the more important bacterial spores [28,29,30,31,32]. Molds are a much more commonly occurring indoor interferent and may be expected to be encountered more frequently in clinical testing environments. Studies have shown that the typical LIBS signature obtained from mold spores can be reliably differentiated from bacterial LIBS spectra with appropriately trained chemometric algorithms [29,31,32,33,34].

Of more concern clinically are infectious fungal spores and yeasts [30]. The ability to identify single spores of the fungi Aspergillus versicolor and Penicillium brevicompactum using a novel electro-dynamic balance-assisted online LIBS apparatus with a dual laser-induced fluorescence (LIF) capability has been shown [35]. Significant differences in the concentrations of the very important elements of calcium, sodium and potassium were inferred from differences in the measured LIBS spectra with the LIF analysis adding the ability to rapidly differentiate these bioaerosols from other aerosol types. The clinically significant infectious yeast Candida albicans ( $C$. albicans) has been investigated because of its role as a significant source of nosocomial or hospital-acquired infections, and the ability to easily differentiate its LIBS spectrum from molds and other bacteria as well as the ability to differentiate specific strains from seven species of Candida (three strains per species) have been demonstrated $[34,36]$.

The use of LIBS for viral identification has been little-studied predominantly because the mass of a virus particle is approximately $10^{9}$ times less than a bacterial cell due to their vast difference in size and also due to the lack of any trace inorganic or metal atoms (e.g. $\mathrm{Ca}, \mathrm{Mg}, \mathrm{Na}$, or $\mathrm{K}$ ) in the virus. The presence of these metals and their strength in the elemental LIBS spectrum is typically what has provided LIBS with its strong bacterial differentiation capability. Nonetheless, some initial experiments have been performed. The ability of LIBS to detect the presences of an MS-2 bacteriophage, which can be used as a simulant of other select viral agents such as the Variola virus responsible for smallpox has been reported [37]. Significantly, the differentiation with LIBS of four strains of live hantavirus responsible for numerous infections across the American southwest was shown in 2012, the first reported demonstration of this capability [38].

\subsection{Summary}

The remainder of this review will concern itself exclusively with those studies which utilized LIBS in bacterial systems. The review will broadly be separated into two sections by chronology. A review of the early years of LIBS-based bacterial identification and classification will summarize the initial demonstrations of this application as well as the initial investigations of chemometric algorithms for classification. Early explorations of the use of femtosecond lasers ("femto-LIBS") for bacterial analysis will be presented in this section as well.

Then the more current work which has aimed to investigate much more specific and targeted aspects of a LIBS-based bacterial analysis will be discussed. A list of current topics of great interest to the field which will be covered includes: a complete analysis of all the chemometric algorithms currently being investigated; the choice of testing substrate and its effect on the LIBS spectrum; the choice of testing gas environment; the nutrient medium used to culture the test samples; detection of bioaerosols as opposed to liquid or solid samples; detection of food contamination; the ability to differentiate individual strains within a given species or alternatively to only perform a genus-level identification; the effect of bacterial concentration, or titer, on the analysis; the effect of environmental stressors on the bacterial cell as reflected by changes in the LIBS spectrum and the effect that other contaminant confusants or interferents have on sensitivity and specificity; the use of standoff or remote LIBS systems for bacterial identification; and the combination of LIBS with other optical modalities ("hyphenated 
LIBS"). The review will conclude with a summarized list of the most important results that have been confirmed by multiple international research groups (Table 1) and a comprehensive table listing the taxonomic identification of all bacteria that have ever been tested with LIBS to date (Table 2), which may be of use to clinical researchers who may only be interested in work on a particular organism as opposed to a review of the broader field.

\section{Early Days}

\subsection{Initial studies}

The first papers describing the use of laser-induced breakdown spectroscopy for bacterial identification, detection, or characterization appeared in 2003 [29,30,39]. These articles describe proof-of-concept experiments that focused almost exclusively on showing that LIBS could indeed yield a sufficient analytic signal when performed on bacterial cells. Morel et al. concluded that compressed bacterial pellets exhibited a homogenous composition which yielded an acceptable root-mean square deviation (RSD) of less than $10 \%$ when LIBS was used for sorting and detection [39]. These authors tested six different biotypes of bacteria, include three bacilli (spore forming) bacteria, and species of Escherichia, Staphylococcus, and Proteus. This group expanded upon this work by developing an aerosol delivery system to illustrate the feasibility of using LIBS to detect biological aerosols [40]. The demonstration of the detection of single cells $(1-5 \mu \mathrm{m})$ in aerosol form had been demonstrated for the first time a year earlier by Hybl et al. in dense clouds and streams [30]. Dixon and Hahn expanded upon this work by detecting single Bacillus spores with a single particle detection efficiency of $0.28 \%$ based on the observation of calcium atomic emission lines, calcium being present in the amount of 2-3 fg/spore [41]. Beddows and Telle also investigated the potential for LIBS to detect single-bacterial aerosol cells in realtime by comparing this method with results from a mobile single-particle aerosol mass spectrometer [28]. They also suggested the use of a dual or hyphenated technique for the application, specifically making the case for a LIBS-Raman or LIBS-LIF measurement to improve upon limits of detection.

Samuels et al., also working with three Bacillus species, concluded that discrimination amongst biotypes such as bacteria, pollen, and ovalbumin ablated on a solid testing substrate (porous silver substrates) was possible utilizing a principal component analysis (PCA), as was discrimination amongst bacteria if better chemometric modelling could be applied to the spectral analysis $[29,42]$. Hybl et al. had also reached this conclusion for aerosol systems in the same year by acquiring LIBS spectra from Bacillus globigii (B. globigii) and discriminating them from spectra obtained from other biotypes such as pollen, fungus/mold spores, growth media (LB broth and brain-heart infusion), and ovalbumin by also performing a principal component analysis [30]. Shown in Figure 1 are the results of these authors' analysis, which shows a clear differentiation between the B. globigii and the other biotypes using only the first three principal component scores. The spectra were acquired from a single laser shot and the data was down-selected to retain only the intensities of thirty strong lines observed in the spectra. Although these authors admitted that this study did not push the limits of chemometrics, both these 2003 manuscripts provided early indications that the use of chemometric methods would play a powerful role in the utility of LIBS for bacterial identification.

Using five strains of bacteria, including one Escherichia coli (E. coli) strain and four Bacillus strains, Kim et al. demonstrated that the bacterial composition as reflected in the LIBS spectrum does not change after aging and performed bacterial differentiation based on intensity ratios of calcium and phosphate relative to unidentified "organic species" [43]. Such emission features from the remnants of organic molecules and also from calcium and phosphorus are fairly ubiquitous in the LIBS spectra acquired from 
biological specimens. To overcome this, Kiel et al. showed that by restricting analysis only to those metals endogenously present and added by preferentially "tagging" cells using custom specific binding agents tagged with exotic metals such as scandium and europium, the identification of Bacillus spores could be performed with a high degree of confidence [44].

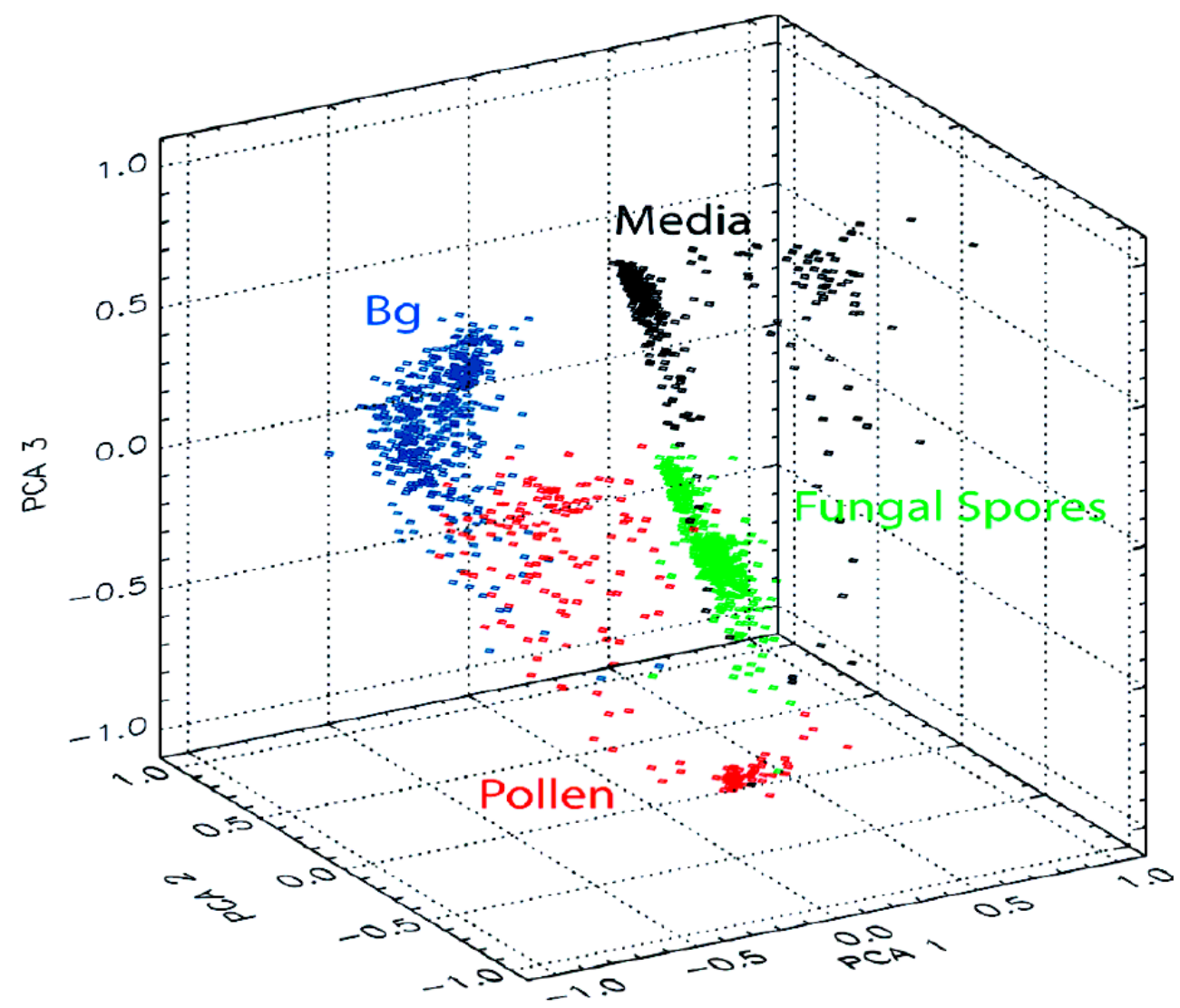

Figure 1. A principal component analysis of LIBS spectra was used to generate a three-dimensional scatter plot showing a clear differentiation of the spectra acquired from B. globigii bacterial spores (BG), three types of pollen, three types of fungal/mold spores, and three types of growth media. Reprinted from reference [30].

\subsection{Early fs-LIBS}

The initial experiments to compare the analytical performance of femtosecond LIBS ("fs-LIBS") to ns-LIBS when utilized with biological specimens were performed in 2003. Femtosecond-LIBS on biological specimens is intrinsically difficult due to the low pulse energy common to most fs systems and the high water content of living biological cells both of which contribute to the formation of low signal-to-noise spectra. In this study, $180 \mu \mathrm{J}$ pulses were used to analyze the epidermal wall of sunflower seedling stems. Full LIBS spectra could not be obtained, but the Ca II emission was sufficient to allow precise analysis of the epidermal wall without completely destroying the peripheral cell wall. Thus, one of the primary advantages of fs-LIBS, high spatial resolution with extremely non-destructive sampling, was retained [45]. 
These studies were quickly followed up by Baudelet et al. in a series of papers which investigated many aspects of fs-LIBS when applied specifically to bacterial cells $[46,47,48,49,50]$. The initial results clearly showed that fs-LIBS could yield high signal-to-noise spectra from solutions of bacteria deposited on cellulose membrane filters [46]. Shown in Figure 2 is a typical LIBS spectrum from this group obtained by ablating $E$. coli cells with a $4.5 \mathrm{~mJ} 120 \mathrm{fs} 810 \mathrm{~nm}$ laser pulse. Significantly, these spectra obtained by femtosecond excitation evidenced clear emission from a very weak potassium line not visible in ns-LIBS spectra and also strong emission from CN molecular bands. The CN (0-0) band in bacterial LIBS spectra has been attributed to the direct ablation of native $\mathrm{CN}$ molecular bands and not recombination with ambient nitrogen within the plume post-ablation [46,49]. These molecular signatures can be clearly seen in the inset of Figure 2. The kinetics or time evolution of that band head intensity thus can be used to provide a signature of the biological medium and differentiate it from a non-biological carboncontaining substrate [47]. This intriguing idea was expanded upon and extended to the nanosecond regime when using UV (266 nm) quadrupled YAG pulses for the ablation of organic samples [50]. It was shown that the time evolution of the line intensities of $\mathrm{O}$ and $\mathrm{N}$ and the $\mathrm{CN}$ molecular band could be used to identify and discriminate native atomic or molecular species from organic targets from those generated through dissociation or recombination with ambient air molecules in the plasma. To date, this idea has not been widely pursued for background discrimination in bacterial spectra.

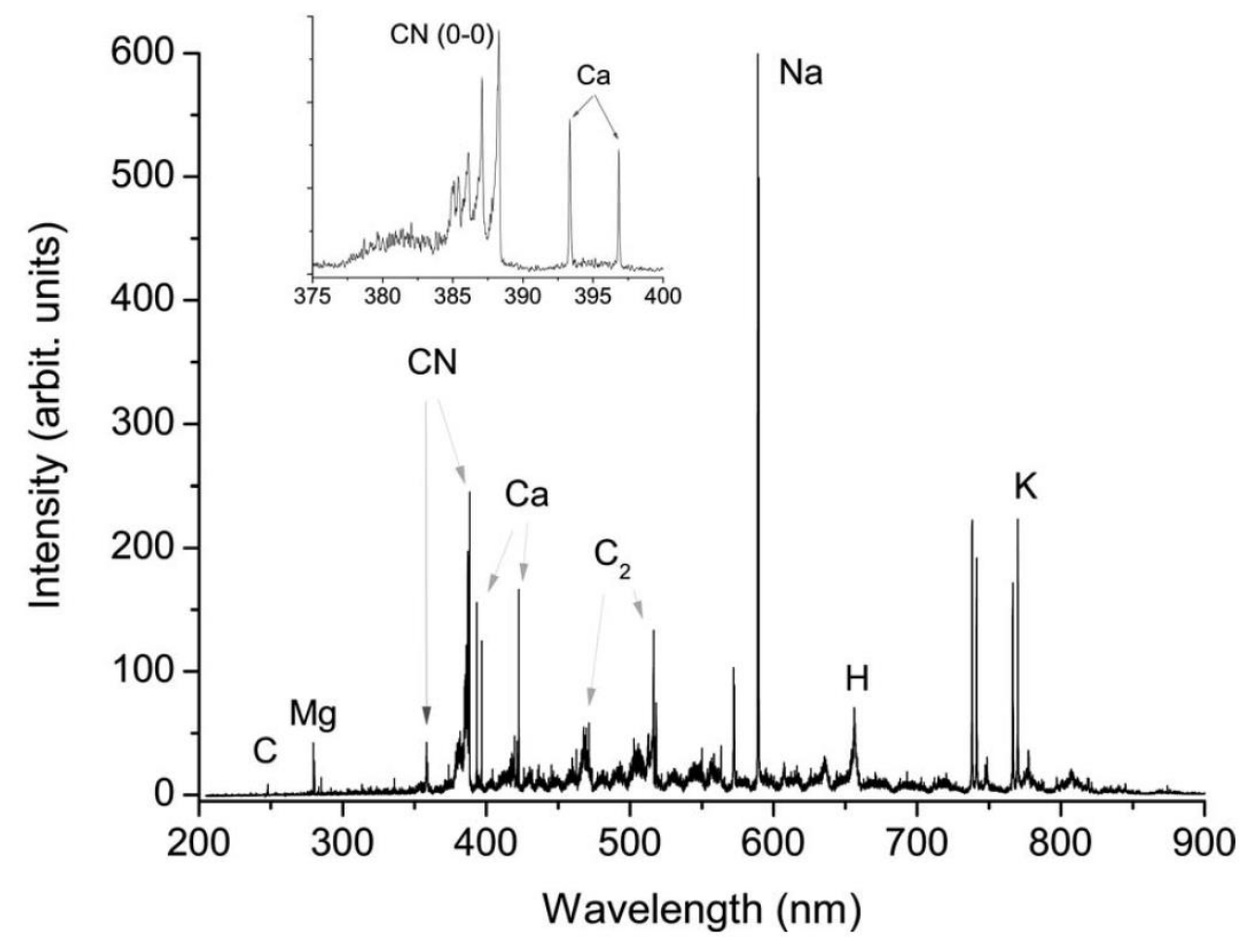

Figure 2. A typical fs-LIBS spectrum obtained by ablating $E$. coli deposited on a nitrocellulose filter with a $4.5 \mathrm{~mJ} 120 \mathrm{fs} 810 \mathrm{~nm}$ laser pulse. The time-integrated broadband spectrum from $200 \mathrm{~nm}$ to $900 \mathrm{~nm}$ was collected by an Echelle spectrometer equipped with an intensified charge-coupled device camera. Shown in the inset is the portion of the spectrum indicative of significant ablation of native $\mathrm{CN}$ and $\mathrm{C}_{2}$ molecular bonds. Reprinted from reference [49] with the permission of AIP Publishing. 
The fs-LIBS spectra possessed adequate signal-to-noise and contained sufficient information to allow a discrimination of five different species of bacteria based on the relative concentrations of $\mathrm{Na}, \mathrm{Mg}, \mathrm{P}, \mathrm{K}$, $\mathrm{Ca}$, and Fe. The discrimination was performed on line intensities from those elements using a method called trace element hyperspace classification (TEHC) [48]. The projection of the bacterial data into a lower dimensional space yielded an analysis of similarities in the biologic properties of the bacteria, showing a general grouping of four Gram-negative bacteria on the basis of their relative calcium concentration as compared to a Gram-positive species.

\section{Selected topics in the development of LIBS for bacterial identification and discrimination}

In the decade subsequent to the early experiments investigating the use of LIBS for bacterial identification (2003-2007), the number of approaches utilized by researchers for bacterial sample preparation, testing, and data analysis has exploded. The number of different species of bacteria tested has grown as well to include more medically relevant species and strains, as opposed to a concentration on Bacillus or other spore-forming species and strains that function as surrogates for $B$. anthracis, the organism responsible for anthrax. This indicates a shift in the area of emphasis being investigated from bio-terrorism protection to clinical diagnosis. This section will summarize the progress made in these various areas, all of which must be more fully developed before LIBS can be realistically adopted as an accurate and reliable analytic technique for bacterial identification.

\subsection{Chemometrics}

While the experimental approaches for preparing, mounting, and then ablating bacterial specimens has varied widely from group to group, the choice of how to analyze the spectral data once obtained has always exhibited the greatest variation of any aspect of these experiments. It is also the area that has evidenced the most dramatic progress and it continues to be an active area of research. In some of the early experiments previously described, it was initially believed that a univariate analysis of the intensities or ratios of intensities of certain lines in the LIBS spectrum (e.g. Ca or Mg) could provide sufficient information to discriminate the bacteria $[28,39,40,43,44]$. Other groups utilized modified linear correlation techniques [42] comparing the relative intensities of one or several elements [48].

\subsubsection{PCA}

It was widely recognized that the mathematical machinery of multivariate analysis as utilized in efficient unsupervised or supervised chemometric algorithms could greatly enhance discrimination sensitivity and specificity. Specifically, a principal component analysis (PCA) was quickly utilized and it was found that even one principal component (PC) could discriminate Bacillus spores from other biological interferents [29] and that the use of three PC's could significantly discriminate Bacillus spores from other very similar biotypes [30] as was shown in Figure 1.

The use of these chemometric algorithms provided at least two other significant benefits that were immediately appreciated. First, the data reduction was significant, as LIBS spectral data are routinely composed of 1024 elements at a minimum, and frequently possess much larger array sizes. A very large fraction of the information in the spectrum that allows reliable discrimination (the variance in the data) can be distilled to a small handful of variables, numbering anywhere from as small as one, two, or three as shown earlier, to a slightly larger number of variables as the complexity and similarity of the data increases. 
Secondly, the construction of a multivariate analysis invariably involves the computation of the ratios of line intensities as opposed to absolute intensities. That is, it is the relative intensity of every channel in the spectrum to every other part of the spectrum that is important, not the absolute intensity of any one channel or emission line. This greatly reduces and can even eliminate the noise introduced by the intrinsic LIBS shot-to-shot variation and significantly reduces experimental complexity. As observed by the authors in [30], this allowed them to completely ignore effects like chromatic focusing aberrations (of the plasma emission into the spectrometer), wavelength-dependent CCD response, or wavelengthdependent spectrometer transmission due to grating efficiency. Such effects, present in every spectrum, are not expected to change and should never alter the relative measured intensities.

The issue of how best to utilize chemometric algorithms was examined by Munson et al. who proposed to specifically investigate a number of statistical strategies to compare discrimination potential in chemical and biological warfare simulants [32]. In this manuscript, they utilized linear correlation, PCA, and soft independent modeling of class analogy (SIMCA) and compared the performance of each in discriminating the single-shot LIBS spectra from three Bacillus organisms, B. thuringienesis, B. globigii, and $B$. cereus, from common interferents like pollen and mold. To reduce the number of variables (wavelengths) in the analysis and lessen the computing requirements, the authors selected regions of the spectrum which contained major emission lines from known constituent elements and excluded other regions of the spectrum which apparently possessed little or no information relevant to discrimination. This choice to only use a sub-set of the acquired data ("variable down-selection") versus keeping all of the spectral data acquired ("full-spectrum analysis") is still very much a topic of significant inquiry.

In an important early work, Merdes et al. analyzed 2048 element data sets (full-spectrum analysis) with a PCA which reduced the data size to 11 dimensions or loadings and also with a linear discriminant analysis (LDA) which was performed on the 11 principal components obtained from the PCA [31]. They also performed a hierarchical cluster analysis (HCA) applied against their training set data to develop an objective classification tool to assist in classifying the members of a test set. Utilizing these tools applied autonomously in Matlab code, they demonstrated a $1 \%$ false positive rate and a $3 \%$ false negative rate for Bacillus subtillis (B. subtillis) specimens when being discriminated from molds, pollen, proteins, and starches. The use of more supervised techniques (such as LDA) upon data that has first been preprocessed by an unsupervised PCA to reduce the dimensionality of the data is now an extremely common technique, as is the use of the dendrogram output of an HCA for data classification. For example, just recently Liao et al. have utilized a PCA followed by an HCA to discriminate 3D surfaceenhanced Raman spectroscopy (SERS) spectra (taken in conjunction with LIBS data) of E. coli, Staphylococcus aureus (S. aureus), and Salmonella typherium (S. typherium) [51]. An example of such a dendrogram resulting from a hierarchal cluster analysis is shown in Figure 3 


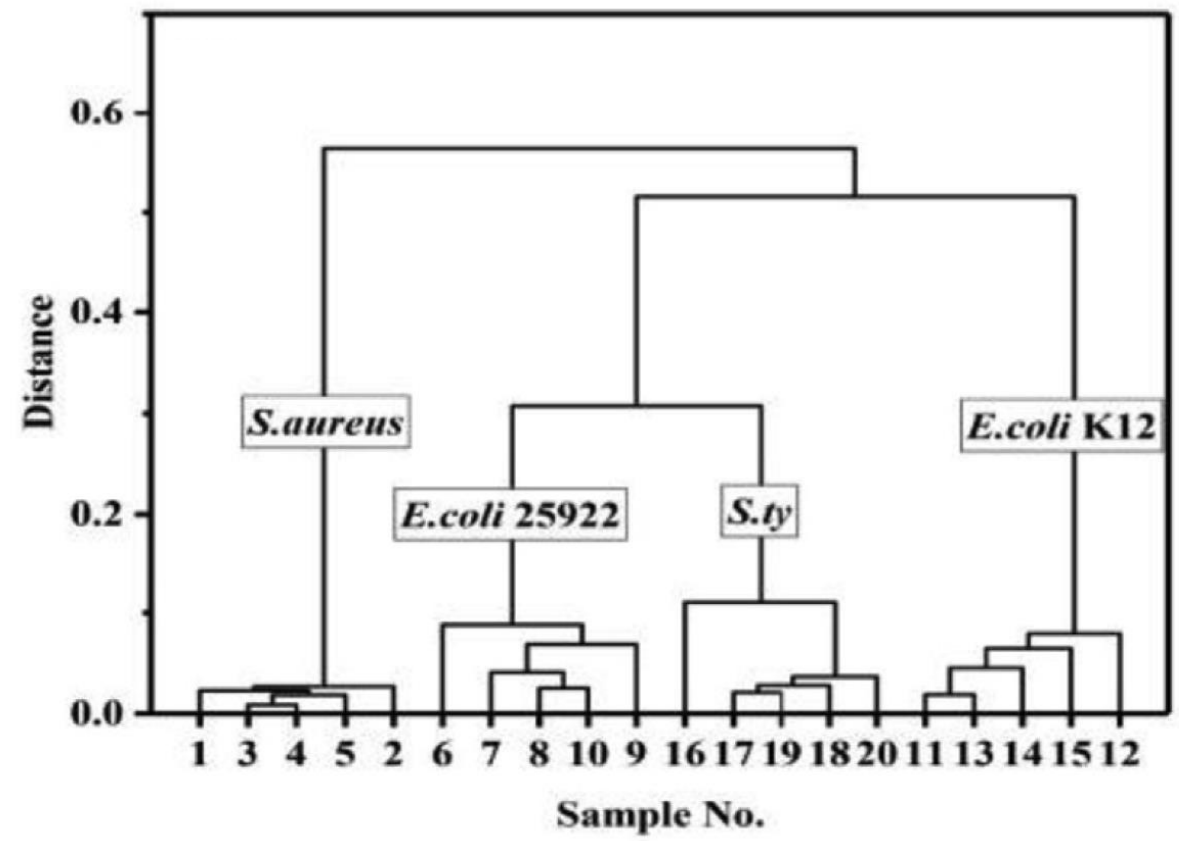

Figure 3. A typical dendrogram plot resulting from a hierarchal cluster analysis of four bacterial strains. Reprinted from reference [51] with permission from Elsevier.

\subsubsection{Neural Networks/Support Vector Machines}

Numerous other chemometric algorithms have been investigated. Neural network (NN) analysis (sometimes referred to as "artificial neural networks") was compared directly with multiple linear regression models to discriminate $B$. atrophaeous spores [52]. The NN models indicated that LIBS could possibly be as sensitive or more sensitive than other methods available at the time. The study of NN models continues today $[36,53,54]$ with many variants of the technique possible, including the use of a K-means classifier on the full-spectrum LIBS data for the discrimination of E. coli from S. aureus [55] and the use of a supervised technique utilizing self-organizing maps (SOM) upon spectra that were first preprocessed in a PCA [56]. In this last, while the first five PC's were seen to only retain $23 \%$ of the variance in the data, a plot of the scores of the first two PC's showed a fairly consistent discrimination between Staphylococcus sciuri, S. aureus, and E. coli. Overall classification success rates varied from as low as $45 \%$ up to $100 \%$ for a variety of bacterial species and strains using this technique.

Cisewski et al. investigated a new approach by using a linear model to pre-process spectra possessing 13,701 channels to first reduce the dimensionality of their data and then built a classification model using a support vector machine (SVM) classification whose only goal was to categorize an unknown spectrum as a Bacillus spore or not [57]. The method performed well, exhibiting a 3\% predication error, and demonstrated the impact that careful pre-processing, including outlier removal and wavelet transformation of the LIBS data, could have.

\subsubsection{Discriminant Function Analysis / Partial Least Squares}

Two of the most commonly reported chemometric algorithms have been discriminant function analysis (DFA) and partial least squares (PLS). PLS is frequently performed with a subsequent analysis to further improve classification, such as with a discriminant analysis (PLS-DA) or a regression analysis (PLS-RA). 
Our own group has made extensive use of a discriminant function analysis on down-selected variables (emission line intensities) from bacterial LIBS data. Initially 19 variables (intensities) from six elements were utilized in a DFA to completely discriminate three strains of the bacteria $E$. coli from each other as well as the common yeast $C$. albicans and a wild type mold [34]. This was the first demonstration of strain-level discrimination in a bacterial system. Pushing the specificity of this method, 19 independent variables were again used to produce nearly $100 \%$ discrimination between four strains of $E$. coli including a pathogenic strain $(\mathrm{O} 157: \mathrm{H7})$ and to investigate discrimination based on spectrum alteration when two strains were cultured in different media [58]. Lastly, this identical technique was used to discriminate two strains of $E$. coli from Pseudomonas aeruginosa ( $P$. aeruginosa), demonstrating no sensitivity to growth medium unless the membrane was intentionally altered by growth on a MacConkey agar which contained bile salts known to disrupt membrane integrity [59].

The number of independent variables used as predictor variables plays an important role in the ability of any chemometric algorithm to predict the membership class of an unknown dataset. When possible, greater numbers of variables should be utilized as was shown when the number of variables was increased to 26 by ablating targets sequentially in two different gas environments [60] and then 31 by ablating in an argon environment [61]. Increasing the number of variables increased classification power, resulting in a $91.4 \%$ differentiation of $P$. aeruginosa specimens from $E$. coli specimens due almost completely to the variance in the data used to construct the first discriminant function (DF1).

The number of independent variables in our data was reduced to 13 because of the decrease in overall emission intensity caused by shooting the bacteria on a watery agar substrate [62]. This analysis still yielded $100 \%$ discrimination between E. coli, Streptococcus viridans (S. viridans), and Mycobacterium smegmatis (M. smegmatis) (wild-type or WT strain) when used to investigate the effects of mixtures and concentrations. Identical data acquisition and analysis were used to investigate the effects of metabolic stressors on the discrimination ability [63] and to construct a 669-spectrum library composed of spectra from five different bacterial genera (Escherichia, Streptococcus, Staphylococcus, Enterobacter, and Mycobacterium) and 13 distinct taxonomic groups (species and strains of those genera) [64]. The results of a DFA performed on the 699 spectra when used to construct a library in two different ways are shown in Figure 4. In Figure 4a, the spectra were grouped in a library by their known genus, and in Figure 4b the spectra were grouped in a library according their known unique taxonomic identity. These DFA libraries were tested using external validation techniques. External validation means that none of the tested spectra was ever tested against a library that contained any other spectra of that organism acquired at the same time or in the same data run. This validation was compared against a less-reliable "leave-one-out" classification (LOO). The effect that using a LOO had on artificially improving sensitivity and specificity was reported and specifically warned against. 

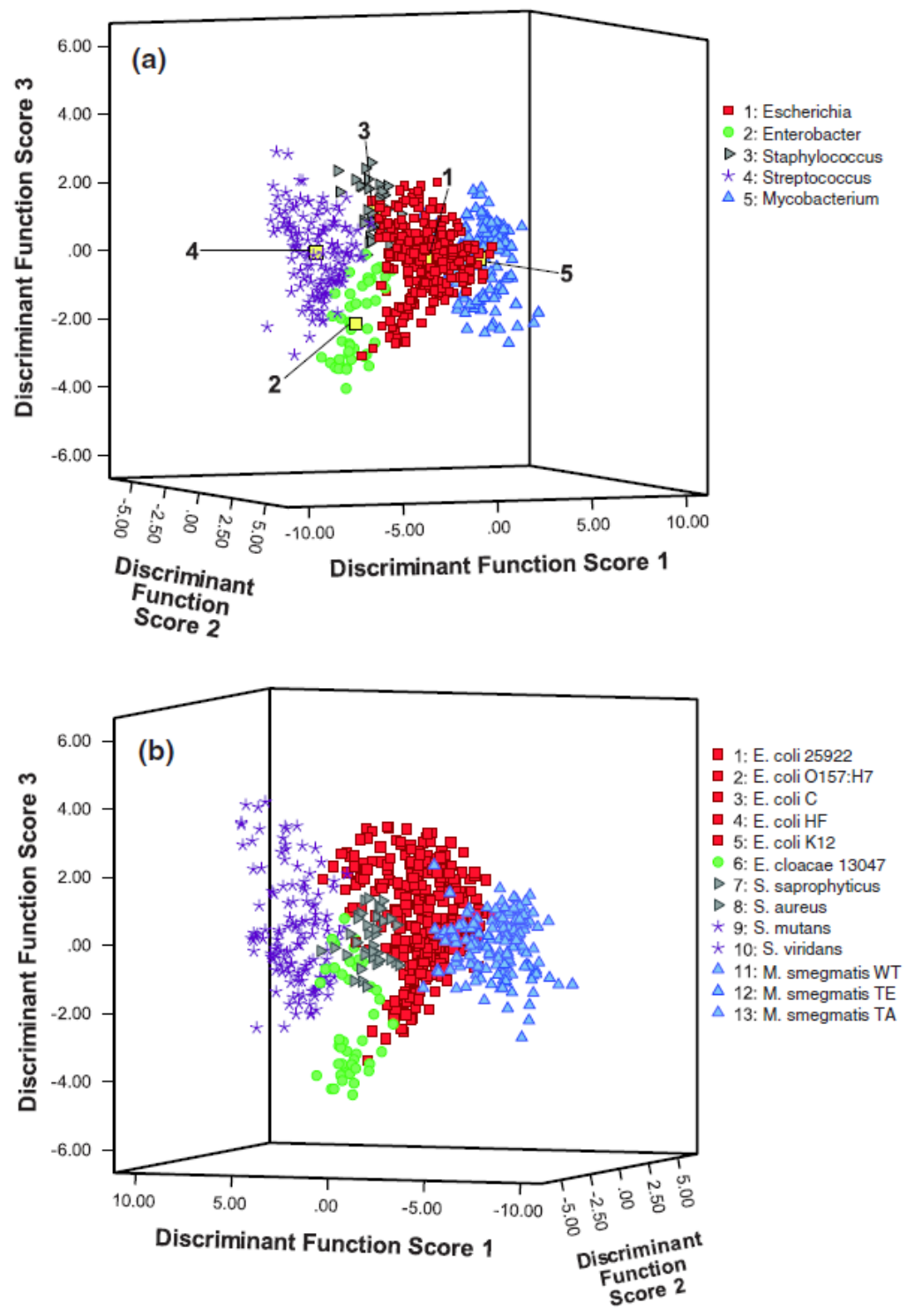

Figure 4. The results of a discriminant function analysis of 699 LIBS spectra when the spectra are classified in two different ways. In 4a, the spectra were classified in five groups based on their known genus-level identity. In $4 \mathrm{~b}$, the spectra were classified into 13 groups based on their known species- or strain-level identity. Data are plotted as a function of only their first three discriminant function scores for visualization. Reprinted with permission from reference [64], [The Optical Society].

This study also demonstrated the utility of using chemometric algorithms sequentially to assist in classifying highly similar specimens such as those from the genera Escherichia and Enterobacter, an idea promulgated earlier by Multari et al. to extract the maximum classification ability from a pre-compiled library of known spectra $[65,66]$. Specifically the five-genus level DFA was applied first to broadly classify unknown specimens as one of those five genera. Utilizing that DFA model, $269(89.97 \%)$ of the 
299 Escherichia spectra were correctly classified and 21 spectra (7.02\%) were incorrectly classified as Enterobacter. The rest were incorrectly identified as another genus. However, when those 299 spectra were analyzed in a two-class DFA using a library generated only from E. coli and Enterobacter cloacae (E. cloacae) spectra, 290 (96.99\%) were correctly classified and only 9 (3.01\%) were incorrectly classified as Enterobacter.

The number of independent variables used to classify our 699-spectrum library was increased and the effect that this had on classification ability was investigated by constructing two new models: one of 24 independent variables from sums and complex ratios formed from the 13 initial down-selected variables and one of 80 independent variables formed from simple ratios of the initial 13 variables [67]. This approach was first demonstrated successfully by Gottfried et al. in the discrimination of explosive residues $[68,69]$. Using this expanded "ratio model" the performance of DFA was compared directly to the performance of partial least squares - discriminant analysis (PLS-DA). Both algorithms behaved adequately in this analysis, returning sensitivities and specificities greater than $90 \%$. Interestingly, it was observed that the DFA was a more appropriate algorithm when the identify of a specimen was completely unknown and a genus-level identification was directed, while a more precise identification at the species-level or strain-level could then subsequently be performed using a PLS-DA, which possessed superior discrimination ability between highly similar spectra. No one algorithm was found to be preferred or superior in all circumstances using this 699-spectrum model. Gottfried later provided an extensive description of a method to construct an optimal discrimination model when using PLS-DA which was found to be highly effective at discriminating LIBS spectra from residues of interest when sampled on various substrates and in the presence of similar and dissimilar interferents [37].

By ablating bacteria on more robust nitrocellulose paper filters, the number of independent variables used to characterize each spectrum in our analysis was increased recently to 164, constructed from 19 down-selected emission intensities and simple ratios constructed from those 19 intensities. 1513 spectra were classified using both DFA and PLS-DA in an externally validated classification. Both algorithms possessed sensitivities and specificities greater than $97 \%$ in a four-genus library composed of Escherichia, Staphylococcus, Pseudomonas, and Mycobacterium [70].

Other investigations of variations of PLS have been conducted. Lewis et al. compared the use of both PCA and a PLS regression which required two sets of sample variables (obtained from the data and defined by the user) to describe the model to classify and discriminate bacteria isolated from reclaimed bauxite soils in Jamaica [71]. Both algorithms showed discrimination ability, but the authors concluded that due to its relations to linear discriminant analysis, PLS was the superior choice for pattern recognition when compared to PCA.

In the work of Multari et al. above [65], the authors utilized a partial least squares approach known as PLS2, a method in which several variables may be modeled simultaneously in cases where there may be correlations between those variables. Once an appropriate model is constructed, unknown specimens can be tested to produce so called predictor values or variables which typically run from 0 to 1 and relate the confidence in the assignment of the unknown test sample to one of the model sample classes, as is shown in Figure 5, a PLS-DA test for Mycobacterium identification. In this analysis, spectra from four "non-Mycobacterium" genera were classified with a predictor variable scattered around 1 , and the Mycobacterium spectra were classified with a predictor variable scattered around 0 . An external validation was performed by classifying spectra of $M$. smegmatis strain TA. No spectra from that strain were used in the construction of the PLS library. The predictor scores of the test spectra are shown at 
the far right of Figure 5, with $100 \%$ of them classifying as Mycobacterium by falling below the discrimination line.

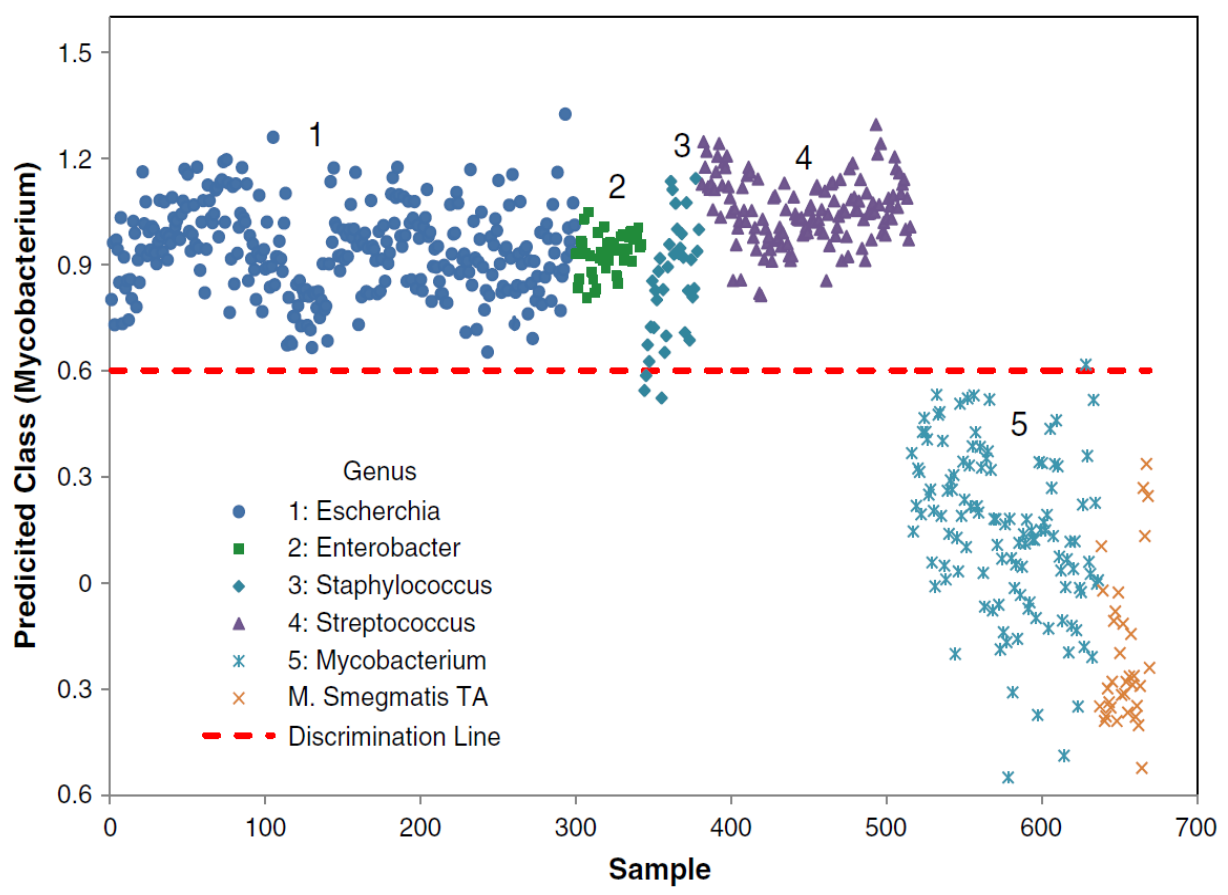

Figure 5. A five-genus PLS-DA test for Mycobacterium identification. Spectra from four genera of bacteria were entered as a "non-Mycobacterium" class and spectra from two strains of Mycobacterium smegmatis (TE and WT) were entered as a Mycobacterium class. Test spectra from a third Mycobacterium strain were tested with this PLS-DA (the orange x's at far right) and were correctly classified $100 \%$ of the time. Reprinted from reference [67] with permission from Elsevier.

Multari et al. also utilized a single variable PLS combined with PCA [38,66,72]. In PLS1 only one variable is modeled. Variations in a single response variable (defined typically as a $Y$ variable) which again typically runs from 0 to 1 are correlated to variations in the predictor variables (defined typically as the $X$ variables). In the analysis of these bacterial spectra, the X-variable datasets were the full LIBS spectrum (4096 channels, each channel an independent variable) of the bacteria. In the work of Putnam et al. [67] the X-variable datasets possessed either 24 or 80 independent variables, constructed from ratios of emission line intensities as described above. In Malenfant et al. [70] the X-variable datasets were 164 independent variables constructed from ratios of the emission line intensities.

\subsection{Testing substrates}

The mass of useful analytic material ablated when testing bacterial samples with LIBS will most likely be low due to the small number of cells present in realistic medical or food-preparation specimens. No matter how low the mass, the cells must be prepared ("mounted") on a target substrate prior to LIBS testing. The exception to this is the testing of aerosols, described below. Problematically, when the mass of analyte mounted on a testing substrate is small, it is expected that the underlying substrate will be unavoidably ablated with the desired analyte, particularly when nanosecond pulsed lasers such as the Nd:YAG laser, are used. For low cell titers, the ratio of analyte mass to substrate mass in the resulting LIBS plasma can be small, and if the testing substrate is composed of many of the same 
elements as the bacterial cells, a loss of diagnostic ability is expected. Because this complication is almost certain to be encountered in any LIBS bacterial testing experiment that does not utilize culturing or re-growth to increase cell count, it has been noted that the choice of substrate can be expected to strongly impact the success of differentiation [38]. These authors noted that a careful study of how best to mount and then sample the bacterial specimen so as to produce the most optimal classification or discrimination must be considered to be an intrinsic part of the creation of any realistic LIBS-based diagnostic technology. The substrate upon which the bacterial cells were mounted in every experiment described in this review is given in the summary Table 2 at the end of this review.

\subsubsection{Pressed pellets}

Early experiments avoided this problem altogether by utilizing freeze-dried or lyophilized bacterial cells. An unrealistically large number of cells could be accumulated in such a way to allow pressing into a solid "pellet," which is an approach typically used for the LIBS testing of unknown powders or residues. Lyophilization is essentially a lengthy freeze-drying process that involves freezing at low temperatures ($80^{\circ} \mathrm{C}$ ) for an extended period of time (12-24 h) followed by a vacuum process for another extended period of time (12-24 h). The result is a light dried powder that when sampled directly with LIBS, tends to be highly disturbed by the impact of the laser pulse $[52,65]$ reducing the amount of analyte sample actually analyzed unless secured by some means, double-sided sticky tape being a common one [33]. While the lyophilization process provides an unrealistically large amount of bacteria and requires entirely too much time to make it a realistically competitive diagnostic technology, the powder derived can then be compressed mechanically to form solid pellets that withstand pulsed-laser interrogation, possess a highly-uniform smooth testing surface, and produce higher intensity LIBS sparks due to the absence of water $[39,40,48,57]$. Such pellets can be repeatedly tested and may even be mixed with a chemically inert binder to provide greater stability [73]. The elemental composition of the pelletized samples, as determined by LIBS should be the same as in samples not prepared in such a way.

\subsubsection{Aerosols}

To avoid the sampling of a mounting substrate completely, several authors have tested bacterial cells or spores in aerosol form, where the only LIBS background expected will be from the atmospheric testing environment or background interferents such as dust, pollens, etc. Much of this work occurred early on in the investigation of the LIBS diagnostic ability and has been discussed earlier. Dixon and Hahn carefully investigated single-shot LIBS detection of $B$. atrophaeous in a stream of pure dry air with the carbon dioxide removed [41]. Light scattering allowed a total particle count within the aerosol stream. By monitoring the calcium emission at 393.4 and $393.6 \mathrm{~nm}, 12,000$ laser shots produced 35 confirmed spore hits when operating at a $5 \mathrm{~Hz}$ repetition rate in an aerosol concentration of $5 \mathrm{~cm}^{-3}$.

Hybl et al. investigated aerosol detection in both dense clouds formed from laser-induced shock-wave disruption of piles of powder and also single particle detection in a dilute air stream [30]. Using an $\mathrm{Nd}$ :YAG laser operating with a variable repetition rate between 1 and $10 \mathrm{~Hz}$ they were able to achieve aerosol hit rates between a maximum of one hit per 10 shots and a minimum of 1 hit per 50 shots. In the dense clouds, reliable LIBS spectra were acquired on every laser pulse. The authors determined that most likely air concentrators and/or separate pre-LIBS "cueing" or pre-triggering detection would be necessary to increase sensitivity.

In a more recent study, Saari et al. were able to trap and levitate single fungal spores and bacteria particles in an electro-dynamic balance (EDB) trap [35]. The use of EDB allows accurate and repeatable trapping position, which is required for optical interrogation of the particle when using a LIBS laser beam with a beam waist diameter of $19 \mu \mathrm{m}$. Such particles can be measured with both laser-induced 
fluorescence (LIF) and LIBS without the need for the pre-triggering required in an online flow aerosol system. LIF and LIBS spectra were obtained with a Czerny-Turner spectrometer equipped with an intensified CCD camera. Single-particle single-shot LIBS spectra acquired from such particles possessed adequate single to noise for such elements as calcium, sodium, and potassium. The authors observed that when performing such single spore/particle detection, a major limitation may be impurities in the deionized water used to prepare the specimens prior to testing.

Many authors have attempted to ablate live bacterial cells from culture directly on the surface of the growth medium (some form of culturing agar) used to grow them $[43,53,54,56,66]$. The approach is complicated as the colony produced during culturing is not controlled for size or cell number, is not "washed" clean of growth medium contaminants prior to ablation, and lacks the mechanical stability or rigidity required for high shot-to-shot repeatability. Indeed it was observed by one group explicitly that especially when performing nanosecond laser ablation (i.e. with an Nd:YAG laser) an observed "splashing" of the bacterial cells greatly complicated the analysis as the experimental conditions were not at all well-controlled [74]. They noted that living cells presented a higher splashing compared to that of sonicated or autoclaved bacteria, due to morphological changes that occur to the cell during these procedures. As noted earlier, ablation of a small number of bacterial cells invariably involves ablating some amount of the underlying substrate. Growth media frequently possess many of the elements observed in bacterial LIBS spectra, albeit in different proportions. Multari et al. observed that every time the culturing medium was changed the development of an entirely new algorithm incorporating LIBS spectra data from that medium was required to allow efficient discrimination [66]. These complications suggests that this method is sub-optimal, as the growth medium chemical composition can change depending upon the manufacturer of the medium material, the water used to make it, and the skill of the technician making the growth plates. Building these variations into a discrimination algorithm, while necessary, is moving away from a true chemical identification of the microorganism.

To avoid this complication our group advocated depositing the cells after culture as a thin film on a nutrient-free $0.7 \%$ agar medium $[34,58,59,61]$. This medium provided an essentially background-free LIBS spectrum, allowing a very sensitive biochemical discrimination down to the strain-level. More recently, we have utilized a highly convenient microbiological filter medium, which provides a highly stable, reproducible, but non-background-free (especially from carbon) mounting substrate [70]. Such filters, fabricated from nitrocellulose paper, nylon, or other material, have been used extensively by other groups due to their ubiquity and availability $[44,47,49,75]$.

\subsubsection{Food contamination}

The detection and identification of bacteria responsible for foodborne illness presents its own unique challenges to this field. The testing substrates that may be encountered can be expected to vary widely and may include actual food surfaces. Several groups have investigated organisms responsible for foodborne illness on their own and on surfaces that may be encountered in food-handling or foodpreparation environments. Yuan et al. acquired spectra from $E$. coli aspirated onto a filter medium and on a sausage, and also from the sausage itself [76]. Based on the measured $\mathrm{Na}, \mathrm{K}$, and $\mathrm{Mg}$ emission lines, a subtle difference between the blank sausage and the sausage charged with bacteria was observed.

Barnett et al. studied the very important organisms Salmonella enterica (S. enterica) serovar Typhimurium, which is a Gram-negative foodborne pathogen responsible for salmonella [77]. Because this infection is most commonly caused by ingestion of raw meat or dairy products, the bacteria were 
inoculated into liquid samples of milk, chicken broth, and brain heart infusion. LIBS was performed with a $266 \mathrm{~nm}$ laser after $1 \mu \mathrm{L}$ of cells harvested from those three food media was deposited on a silicon wafer. A DFA was used to investigate the ability to discriminate different species of bacteria as well as to differentiate milk spiked with varying concentrations. The DFA analysis worked well, but could not perform as well as polymerase chain reaction (PCR) or quantitative real-time PCR (qPCR), which the authors also performed.

Multari et al. studied the important foodborne pathogens E. coli O157:H7 and S. enterica. They performed a PLS1 analysis of LIBS spectra acquired from live bacteria that had been deposited on various foodstuffs such as eggshell, milk, bologna, ground beef, chicken, and lettuce and also on various food-preparation surfaces such as a metal drain strainer and a cutting board [72]. The authors also collected LIBS data by ablating directly on swabs that are commonly used to wipe surfaces for hygiene surveillance and compliance. In all cases a differentiation of the organisms was demonstrated once a suitable PLS1 model was constructed which incorporated the various background materials.

Finally Gamble et al. investigated the water and wash-waters commonly used in food-processing plants [73]. They studied the pathogens Pseudomonas putida, Listeria innocua, S. aureus, and S. enterica serovar Typhimurium (which is commonly referred to by its serovar identification only as $S$. typhimurium or by its more proper taxonomic identification, $S$. Typhimurium). Six different types of buffer solutions and wash waters with different cation concentrations and $\mathrm{pH}^{\prime}$ s were used to rinse the bacteria prior to autoclaving and overnight lyophilization. Lyophilized bacteria were pelletized in a 15-ton press and stabilized with microcrystalline cellulose. A PCA was used to generate five principal component scores reflective of the main variance in the dataset and then a Mahalanobis discriminant analysis (MDA) was used for classification. Using the five PC scores, the four genera were discriminated from each other with $100 \%$ classification accuracy. Also, within each genus the bacteria isolated using different water types were differentiable. From this fact the authors concluded that the water source used in purification or isolation of the cultures must be precisely controlled for both $\mathrm{pH}$ and the presence of mineral cations. The use of deionized water was recommended over other sources such as reverse osmosis, distilled, and especially tap water due the presence of trace minerals in those types of water.

\subsection{Nutrient media/culturing environment}

The choice of nutritional media upon which or within which to culture bacterial specimens prior to testing with LIBS has been an important experimental parameter that has been investigated by many authors. The intent of the experiments has been to determine the extent to which the local chemical environment present during cell reproduction can ultimately influence the cell's elemental composition and thus the measured LIBS signature.

In an early experiment, Morel et al. utilized two different growth media, an organic compound-based medium and a mineral compound-based medium and showed that the measured phosphorus to carbon ratio was reproducible, so no noticeable effect was observed in the LIBS analysis [39]. While Kim et al. did not utilize different nutrient media, they initially recognized that the length of time in the culture medium could impact a LIBS spectrum, observing that as Bacillus species grew they could selectively take up certain elements out of the culture medium [43]. This effect was especially evident during Bacillus sporulation, a process which does not occur for many medically significant bacteria.

In 2007, Diedrich et al. showed that a discrimination based on a multivariate analysis (DFA) could be independent of the growth medium by culturing a non-pathogenic strain of $E$. coli in both a liquid TSB broth and on a solid TSA plate [58]. Expanding on this earlier work, Rehse et al. carefully investigated 
the effect that culturing on three different solid agar media had on a pathogenic strain of $P$. aeruginosa [59]. The LIBS spectra from the media themselves (a trypticase soy agar (TSA) plate, a blood-agar plate, and a MacConkey agar plate) were also obtained and investigated. Importantly, the MacConkey agar contained bile salts, a medium deliberately chosen to induce bacterial membrane changes. The results of this experiment showed that by intentionally altering the membrane biochemistry, a significant and reproducible alteration of the LIBS spectrum could be induced, but that all three classes of Pseudomonas grown in such a way could still be reliably discriminated from two strains of $E$. coli.

To further investigate this effect, Rehse et al. added a fourth nutrient medium, a TSA plate containing intentionally doped deoxycholate at a $0.4 \%$ concentration, to alter both $P$. aeruginosa and $E$. coli to a maximum extent [61]. Spectra from the media were also compared. Two important conclusions resulted from this; first that the source of $\mathrm{Ca}$ and $\mathrm{Mg}$ observed in the LIBS plasma could be located at least in part to the Gram-negative outer membrane and second that the accuracy of discrimination between two genera of bacteria remained greater than $90 \%$ regardless of the nutrient medium upon with the bacteria were cultured. Changes in the environment of the reproducing cell could indeed be measured by LIBS, but such changes did not inhibit the accurate identification of the bacteria.

This result was confirmed by Marcos-Martinez et al. who investigated $P$. aeruginosa, E. coli and $S$. Typhimurium cultured on three different media: an LB agar; a MacConkey agar, and a Brucella anaerobic agar [53]. In these experiments, only differences measured between the three bacterial groups resulted in classification using a neural network analysis, with no apparent dependence on the growth medium, and the authors thus concluded that the identification did not depend on the culture medium. In addition, the identification analysis was stable over a long period of time and it was observed that minor changes in the experimental conditions did not alter sample identification. Subsequent groups have also investigated the LIBS spectra obtained directly from the media, but could only conclude that sometimes bacterial specimens could be classified as a nutrient broth in a PLS-DA classification but that different nutrient media could be accurately classified, if desired $[37,75]$.

In a demonstration of the utility of environmentally-induced elemental cellular changes, Lewis et al. demonstrated the successful use of fs-LIBS for discriminating amongst various soil bacteria recovered from a variety of soil/growth environments which presumably could exert significant chemical stress on the bacterial cells [71]. They concluded that it was the chemical composition of the bacteria (as influenced by the local soil chemistry) measured by the LIBS fingerprint which served as the basis for successful sample classification.

Malenfant intentionally altered the metal content of $E$. coli by culturing specimens on a typical TSA medium plate that was doped with zinc sulfate solutions at concentrations of $0,100,200$, and $300 \mathrm{ppm}$ [78]. While zinc was not readily distinguishable from noise in the typical E. coli LIBS spectrum, cells grown in the presence of such environmental zinc showed substantial uptake of the element, even after triple washing to insure the removal of contaminating residual growth medium on the outside of the cells. This uptake in cellular zinc as measured by the LIBS spectrum showed a linear relationship with environmental zinc. This is shown in Figure 6, where the phosphorus emission at $213.62 \mathrm{~nm}$ and the zinc emission at $213.86 \mathrm{~nm}$ are shown for $E$. coli cells grown in varying concentrations of zinc. The intensity of that zinc line normalized by the carbon $247 \mathrm{~nm}$ emission intensity shows a highly linear dependence on the zinc concentration present in the culture medium. Conversely, cells grown in an excess of magnesium, readily observed in typical $E$. coli LIBS spectra, showed no such uptake. 

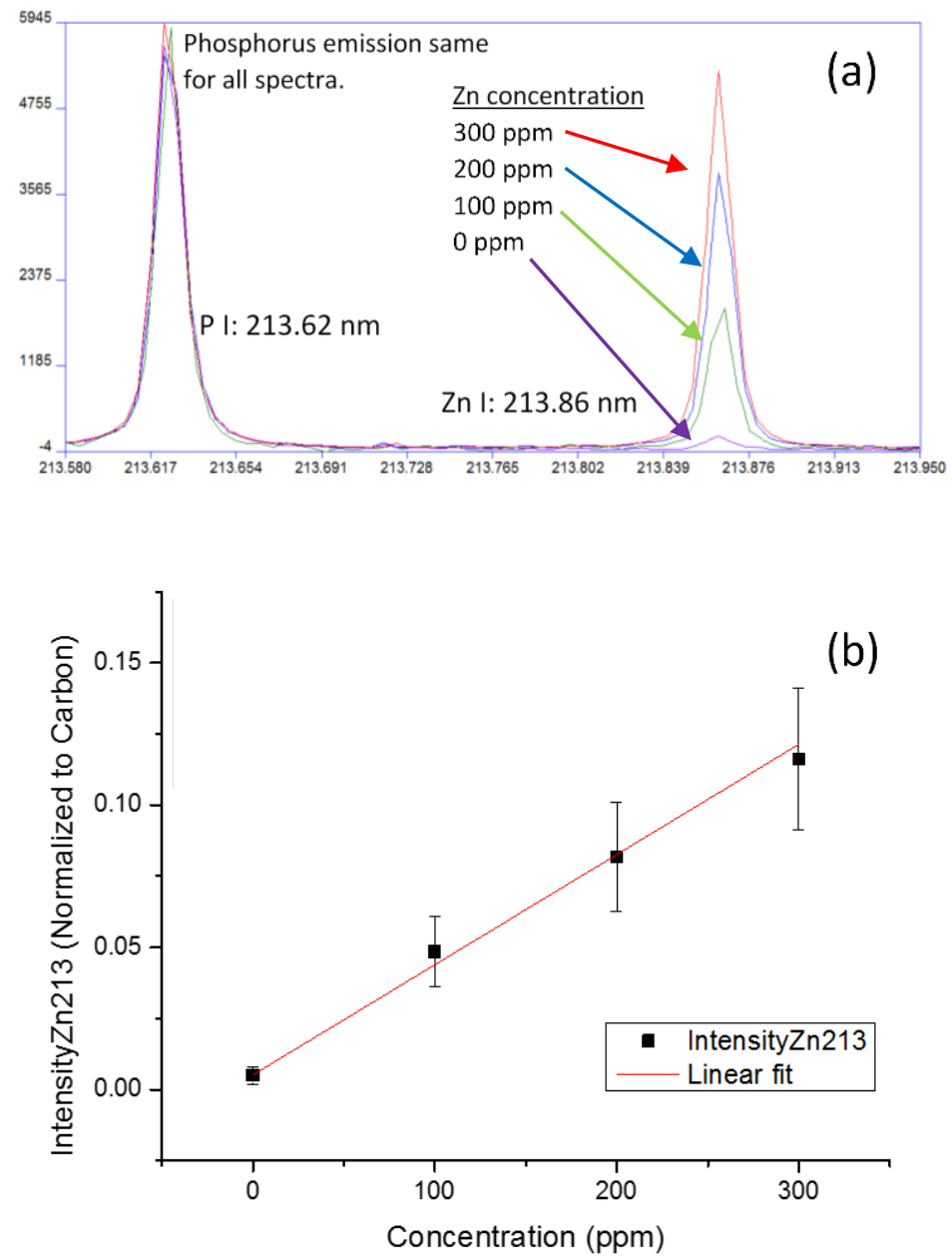

Figure 6. LIBS spectrum from $E$. coli cells cultured in an over-abundance of elemental zinc. As the concentration of zinc in the culture medium was varied from $0 \mathrm{ppm}$ to 300 ppm, a corresponding increase in the LIBS zinc emission was observed (a). No corresponding change in the phosphorus emission was observed, indicating there was no change in the number of cells being tested. A plot of the measured zinc LIBS emission intensity normalized by the carbon emission intensity at $247 \mathrm{~nm}$ resulted in a highly linear dependence of the observed cellular LIBS emission on environmental zinc concentration (b).

It has been mentioned that the water utilized in the preparation of the nutrient media (and in subsequent washing or preparation steps) can play a significant role in changing the measured LIBS spectrum. The water can alter the observed metal content for elements such as $\mathrm{Mg}, \mathrm{Ca}, \mathrm{Na}$, and $\mathrm{K}$ [73]. The use of DI water when possible is suggested, although of course, bacterial isolates obtained from medical specimens without subsequent culturing will not have such tight controls [35].

\subsection{Strain discrimination}

For bacteria prepared in a nominally identical manner, the most sensitive identification/classification possible would be between strains of a single species. The difference between strains is expected to be small, due to the lack of large cellular changes from strain to strain. It is important to clarify that it is not 
the genetic difference between strains that a LIBS-based measurement is able to differentiate, but rather the resulting cellular biochemistry changes that are expressed by the different genetic variants.

The first demonstration of a discrimination between strains of a single organism with near $100 \%$ accuracy was performed by Diedrich et al. in 2007 when three strains of $E$. coli were discriminated utilizing a DFA [34]. All strains were easily differentiated from a C. albicans yeast and the medium on which they were grown. Intriguingly, the two K-12 strains in this work (one a laboratory K-12 strain and one a derivative of that strain) were clearly similar in composition compared to the third environmental strain, Nino C. This provided more evidence that it was a true chemical classification being produced, not merely an algorithmic differentiation. A pathogenic strain of bacteria (E. coli O157:H7, also known as enterohemorrhagic $E$. coli or EHEC) was differentiated from two non-pathogenic strains and an environmental strain of the same organism for the first time by Diedrich et al. who showed a classification accuracy of the four organisms of $97.8 \%, 84 \%, 73.1 \%$, and $88 \%$. In this analysis, the environmental strain Nino $\mathrm{C}$ possessed the most significantly different LIBS spectrum compared to the other microorganisms. This was the first demonstration of the use of LIBS on a common medical pathogen, and the ability to discriminate the pathogen from the non-pathogenic strain of $E$. coli was confirmed in subsequent studies [62,64]. This $E$. coli strain discrimination was enhanced in a dual-gas experiment which utilized both argon and helium sequentially when acquiring LIBS spectra [60]. To confirm the stability of strain discrimination, samples of $E$. coli strain Nino $C$ were tested after being autoclaved, exposed to ultraviolet light and left untreated and these spectra were easily discriminated from the closely related $E$. coli ATCC 25922 . The three Nino $C$ strains produced identical spectra and were not differentiable from each other but were differentiated 100\% from the ATCC 25922 strain [63]. In this article, the Nino $\mathrm{C}$ strain was also cultured in two different media, including the MacConkey medium mentioned earlier. The two specimens of Nino $\mathrm{C}$ were classified as indistinguishable from each other, while being discriminated with 100\% accuracy from the HF4714 and ATCC 25922 strains. This is shown very clearly in Figure 7, which shows the first two discriminant function scores of two DFA tests run on the various specimens. In a much more recent study investigating the dual use of 3D SERS and LIBS, specimens of E. coli K12 and ATCC 25922 were reliably differentiated by a principal component analysis on the basis of their 3D SERS spectra, but LIBS differentiation was not attempted on the specimens.

The rise of antibiotic resistant strains of bacteria (sometimes referred to as multiply drug-resistant or MDR strains) has been an ominous development in modern medical microbiology. Previously easily treated microorganisms have achieved high levels of resistance to the most common antibiotic therapies, leaving physicians with very few, and sometimes with no remaining options for treatment. Some of the most ubiquitous of these are the methicillin-resistant strains of Staphylococcus aureus (MRSA). The first discrimination of these microbes was shown in 2010 by Multari et al. who showed that it was possible to differentiate lyophilized samples of $E$. coli, three clonal MRSA strains, and one unrelated MRSA strain using a PLS2 analysis for discrimination [65]. Spectra from ten unknown samples were $100 \%$ correctly matched to the five reference spectra in a blind study. This investigation was significantly expanded when Multari et al. added multiple strains to their analysis, showing discrimination and identification of eight $S$. aureus strains including four MRSA strains, three of them clinical strains and one a laboratory derived mutant of one of those clinical strains [66]. A correct identification was obtained from thirteen distinct specimens including Acinobacter baumannii, $B$. subtilis, E. coli K12, Klebsiella pneumonia, P. aeruginosa, and the eight Staphylococcus strains. One hundred spectra were acquired from each specimen, 50 were used to build identification models and 50 were used to test the models. Using a specifically constructed sequential algorithm, all specimens were identified in under 2 minutes. 

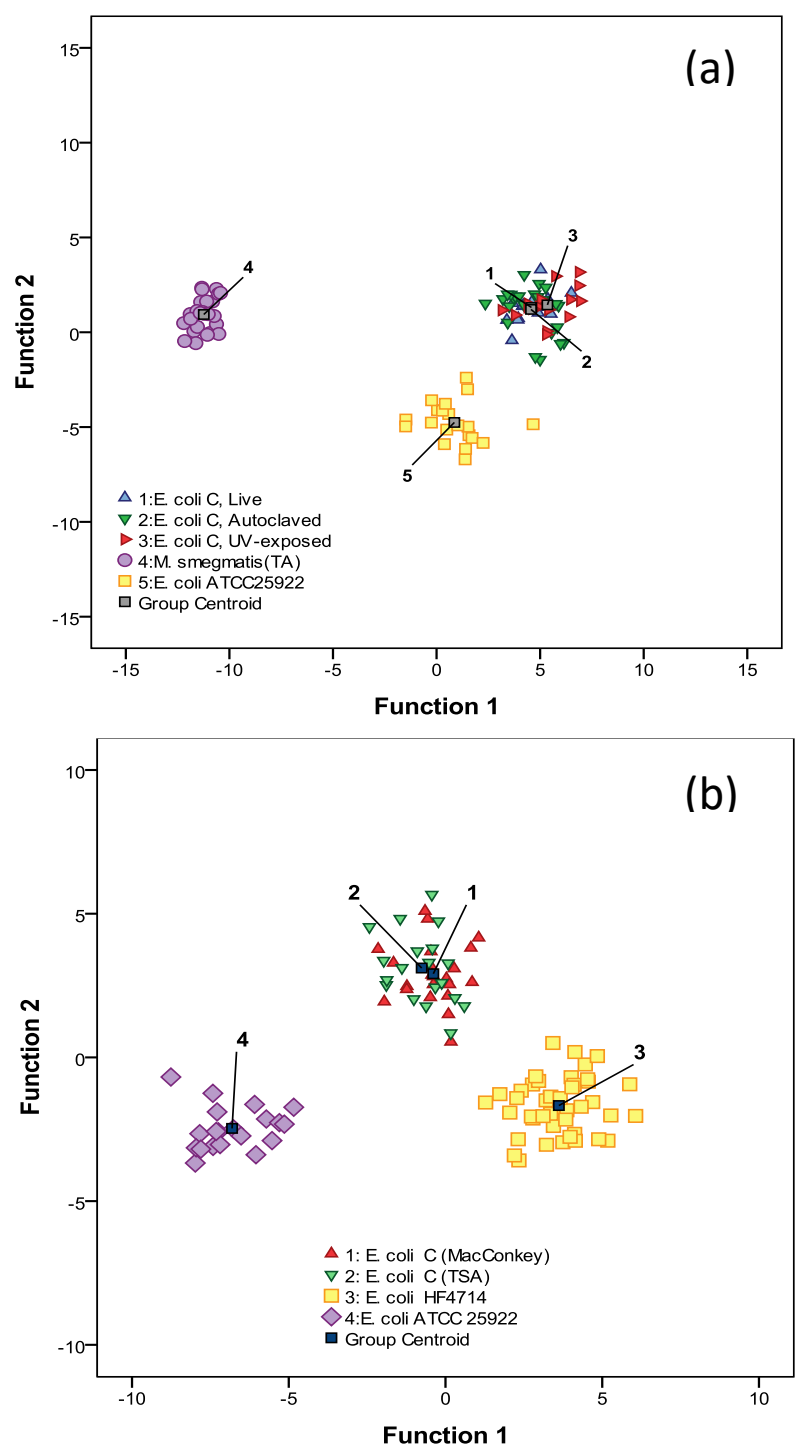

Figure 7. Examples of robust E. coli strain differentiation. (a) The first two discriminant function scores of a DFA performed on five specimens: three samples of E. coli strain C (live, autoclaved, and exposed to UV radiation), one sample of $E$. coli strain ATCC25922, and one sample of M. smegmatis. (b) The first two discriminant function scores of a DFA performed on four specimens: two samples of $E$. coli strain C (cultured on TSA and MacConkey agar), one sample of E. coli strain HF4714 (cultured on TSA), and one sample of E. coli strain ATCC25922 (cultured on TSA). In all cases, the $E$. coli strains are easily differentiated from each other, but an individual strain, when prepared, grown, or treated in a different manner, is classified $100 \%$ correctly as itself.

A combined Raman spectroscopy and LIBS approach was used to investigate MRSA strain differentiation by testing E. coli CCM 3954, S. aureus CCM 4223, S. aureus CCM 47540 (MRSA), S. aureus CCM 3953 (methicillin sensitive or MSSA), Staphylococcus sciuri, and Staphylococcus pseudointermedius directly on an agar growth plate [56]. A PCA was performed on the spectral data, which were then classified using a 
supervised version of Kohonen's self-organizing maps, which is a form of neural networks analysis. Using this method, the LIBS-only classification accuracy of the strains ranged from $45 \%$ to $100 \%$.

A total of 40 strains from a variety of different bacterial species, including E. coli, P. aeruginosa, Klebsiella pneumoniae, S. Typhimurium, Salmonella pullorum, and Salmonella salamae were tested by Manzoor et al. [54]. As performed in [56], specimens were tested directly on the agar medium upon which they were grown and a neural networks (NN) analysis was performed. Eighty spectra from a single growth plate were used to construct the NN model for each strain, and 20 spectra from three different plates were used to test the model (external validation). Successful classification with accuracies better than $95 \%$ showed that an NN model constructed from different strains allowed highly accurate discrimination of strains from the same species, implying that multidrug-resistance and other genetic variations impart significant changes to the elemental composition of the cells that can be detected efficiently by LIBS.

\subsection{Genus and species discrimination}

In many situations a strain-level identification may not be necessary to inform the timely initiation of appropriate pharmacological therapy. It is often necessary only to have a genus-level identification of the infectious pathogen (i.e. Pseudomonas, Streptococcus, or Staphylococcus). Alternately, some genera have so many species and sub-species that an exact knowledge of the particular strain is not ever achieved or necessary. Therefore in many cases the ability of LIBS to rapidly identify the species, or even just the genus, of the organism could be extremely useful. Mohaidat et al. demonstrated this in 2012 with a five-genus DFA that yielded sensitivities of approximately $85 \%$ and specificities above $95 \%$ when tested with an external validation [64]. This result was improved upon by Putnam et al. who obtained a sensitivity in excess of $91 \%$ and a specificity greater than $95 \%$ in an externally validated DFA [67]. In the 2014 study by Manzoor et al. referenced above, the authors performed a species-level test on genera and species most commonly responsible for hospital-acquired infections, including Escherichia, Pseudomonas, and three strains of Salmonella [54]. Based on their NN analysis, these authors concluded that classification of the organisms was based on the major differences in the bacterial LIBS spectral fingerprint at the species level. Gamble et al. utilized a PCA on LIBS spectra after preprocessing and demonstrated complete classification of replicates prepared in an identical fashion of specimens of Listeria, Pseudomonas, Staphylococcus, and Salmonella [73]. Prochazka et al. were able to reliable classify three species of Staphylococcus with $100 \%$ accuracy, even when spectra from E. coli and three different strains of $S$. aureus were included in the test, but only when LIBS spectral data was fused with Raman data [56].

\subsection{Concentration/titer}

The dependence of the accuracy of a LIBS-based classification on the number of cells present in the specimen (or ablated into the LIBS plasma) is a critically important question. In a clinical specimen, the number of cells should vary widely, from a low titer in a specimen from a pre-symptomatic patient, to a high titer in a specimen obtained from a diagnosed infection. Obviously, in cases of food contamination or hygiene surveillance, the cell counts may be even lower, ranging all the way down to zero in a properly sterilized environment. Thus it is not merely the limit of detection (LOD - the number of cells required to reliably provide an adequate LIBS signature to guarantee detection) or the limit of identification (LOI - the number of cells required to reliably provide a LIBS signature with enough spectral information to guarantee classification at some desired sensitivity/specificity) that are of concern, but also the impact on the sensitivity and specificity that the cell count or titer has. Ideally the spectrum obtained from a single cell should be classified exactly the same as the spectrum from a 
sample with, i.e., $10^{9}$ cells, the relative ratio of elements being identical in those two cases. However, due to changes in the LIBS plasma, these two spectra may not classify identically. In some cases, the operator may not desire the classification to be the same, allowing a quantification of the titer in the sample due to its classification against a pre-compiled library.

These effects were investigated by Rehse et al. who performed several experiments to elucidate these effects in 2010 [62]. Samples of M. smegmatis were prepared with a standard concentration of approximately $5 \times 10^{8}$ colony forming units (CFU)/mL and several serial dilutions. The total measured LIBS emission intensity (the integrated area under the curve of all measured LIBS emission lines) was found to depend linearly with concentration. In addition all the reduced concentration specimens were classified with $100 \%$ accuracy using a precompiled library constructed only from the most concentrated "control" specimens, even when a closely related mutant strain of the same species was included in the DFA as an interferent. Lastly, replacement of a fraction of the $M$. smegmatis cells $(10 \%, 20 \%, 30 \%, 40 \%)$ with cells from a different species did not negatively impact classification accuracy until over $30 \%$ of the original cell count had been replaced by a substitute "contaminant" type of cell in a two-class DFA. This experiment was conducted to simulate unintentional contamination of a clinical specimen subsequent to its removal from the patient.

The linear dependence of the total LIBS emission intensity with concentration was confirmed in 2018 by Liao et al. who demonstrated this for both $E$. coli and $S$. aureus concentrations spanning four decades, from $10^{4} \mathrm{CFU} / \mathrm{mL}$ up to $10^{8} \mathrm{CFU} / \mathrm{ml}$ with $\mathrm{R}^{2}$ values greater than 0.97 [51]. Malenfant et al. also reported a linear dependence of the total LIBS emission intensity on the cell concentration when a large number of cells were deposited on a nitrocellulose filter testing medium [70]. In this study, approximately $10^{5}$ cells were ablated per laser shot. This study showed a saturation or flattening out of the response curve at concentrations above $10^{11} \mathrm{CFU} / \mathrm{mL}$.

Barnett et al. tested concentrations of $S$. enterica that spanned eight decades ( $10^{1}$ to $10^{8} \mathrm{CFU} / \mathrm{mL}$ ) as measured by DNA concentrations in the specimens prior to LIBS testing [77]. In blood-heart infusion, chicken broth, and milk, LIBS detection limits were $10^{5} \mathrm{CFU} / \mathrm{mL}$. Using a DFA, these concentrations were reliably discriminated from $E$. coli and the blood-heart infusion, but it was not clear whether the DFA could provide any reliable quantitative information about the concentration. The spectra from the various concentrations did not reliably classify as separate distinct classes.

Multari et al. tested concentrations of $E$. coli and S. enterica that spanned five decades from approximately $10 \mathrm{CFU} / \mathrm{mL}$ up to $10^{6} \mathrm{CFU} / \mathrm{mL}$ [72]. They showed that $S$. enterica in milk could easily be differentiated from uncontaminated milk, regardless of the concentration of the pathogen. E. coli on eggshells could be differentiated with $100 \%$ accuracy from uncontaminated esggshells (spiked with TSB as an interferent) regardless of the concentration of E. coli used. In addition, E. coli and S. enterica at various concentrations could be discriminated from each other with $100 \%$ accuracy when tested on eggshells. This is shown in Figure 8.

Lastly, as discussed earlier in the section on aerosols, spectra from single spores can be detected, demonstrating an LOD of one cell (e.g. [35]). To date, no attempt has been made to investigate the LOI 
of such systems and classify an organism based on its single-cell LIBS spectrum, mostly due to the poor signal-to-noise in such spectra.

\section{E. coli \& S. enterica on Eggshell}

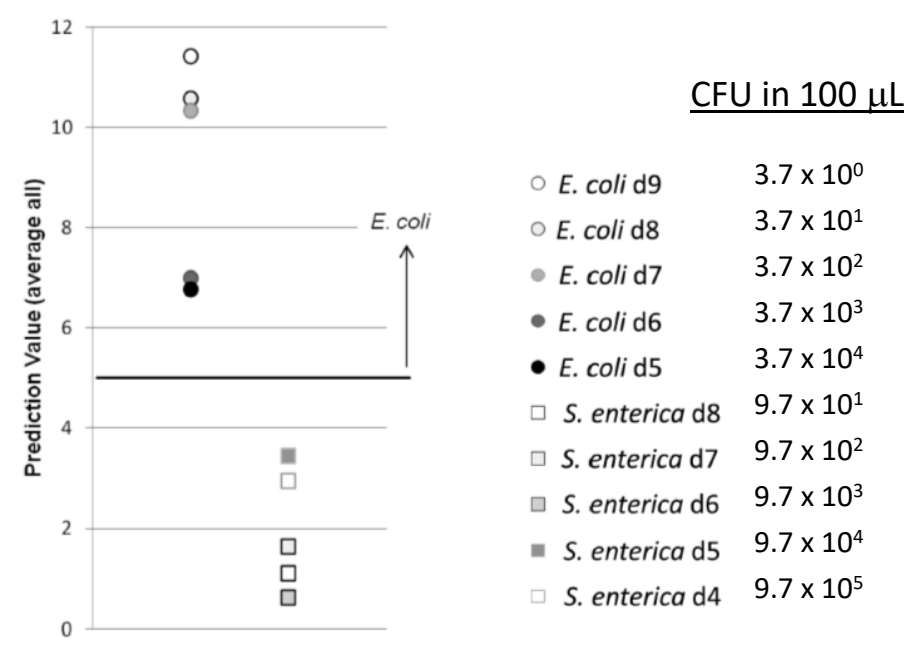

Figure 8. Differentiation of $E$. coli from S. enterica when tested on a common food surface (eggshells) is independent of cell concentration. Reprinted with permission from reference [72]. Copyright (2013) American Chemical Society.

\subsection{Environmental stressors}

Because the identification and classification of bacterial cells is performed in part on the basis of their elemental cellular chemistry, of great concern is the potential change in the measured LIBS spectrum due to real elemental changes in the bacterial cell. Such changes could be caused by environmental factors which induce a biochemical response in the cell. These environmental stressors include influences which can result in complete cell lysis (such as autoclaving or vortex/ultrasonic agitation), loss of reproductive ability (exposure to ultraviolet light), and more subtle changes in cellular chemistry.

Mohaidat et al. investigated this in 2011 by attempting to observe a change in LIBS signature as a function of the metabolic state of the cell by exposing specimens to bactericidal ultraviolet radiation and autoclaving samples prior to LIBS testing [63]. These tests were performed on representative Gramnegative samples, E. coli, and representative Gram-positive samples, S. viridans. Utilizing a DFA, the samples of $E$. coli $C$ were all classified identically as $E$. coli $C$, whether reproducing in the log-phase, killed via autoclaving, or rendered inactive by exposure to ultraviolet light. In addition, these specimens were readily discriminated from specimens of $M$. smegmatis and another strain of $E$. coli (ATCC25922). The $S$. viridans samples behaved identically, indicating that LIBS spectra were not sensitive to the metabolic state of the cell in this regards, which suggests that for practical biosafety reasons, biospecimens could very well be autoclaved first prior to LIBS testing, removing any hazard to operators. Both specimens possessed LIBS spectra of identical absolute intensity (within uncertainty), indicating no inherent loss of signal from inactivated or heal-killed cell.

As well, they tested cells that had lapsed into a dormant state by sitting at room temperature on nutrition free (abiotic) surfaces for periods of time ranging up to nine days. Again, all dormant cells 
classified identically with the cells actively reproducing in the log-phase and those exposed to ultraviolet light and autoclaved. Lastly, they investigated intentional cell membrane alteration by exposing $E$. coli cells to substrates which could be expected to exert a detergent-like action on the cell membrane, particularly a MacConkey agar growth medium containing $0.1 \%$ deoxycholate. Spectra from these cells were altered from those grown on standard growth media but exhibited no changes in classification accuracy compared to $E$. coli grown on standard growth media and were easily differentiated from two other strains of $E$. coli. As mentioned earlier, this result was also confirmed by Marcos-Martinez [53] using a similar MacConkey agar medium.

Understanding the effect of the metabolic state of the cells on a LIBS-based classification is of the utmost importance and has been studied recently. Multari et al. tested E. coli and S. enterica cells that were both viable and heat-killed utilizing a PLS1 algorithm [72]. Differences in the measured LIBS spectra could be used to construct appropriate algorithms to differentiate the killed class from the viable cells. However, when killed and viable cells were grouped together in a test performed on ground beef, these spectra were still readily differentiable from a control spectrum of ground beef uncontaminated by any E. coli. This confirms the results observed earlier that cellular differences may be observed and utilized for a LIBS-based classification of the metabolic state of the cells, but the differences are quite subtle and do not intrinsically alter the spectra so significantly that an incorrect identification would result when trying to discriminate against other bacterial types.

Sivakumar et al. investigated the use of both fs-LIBS and ns-LIBS to investigate the effect that two types of inactivation, autoclaving and sonication, had on the acquired LIBS spectra [74]. Using E. coli K12 as a model system, fs-LIBS proved to be effective for monitoring the metabolic state of the cells when spectra were analyzed with a PCA and unknown spectra were tested using a SIMCA. Key differences in the measured relative intensities of $\mathrm{Mg}, \mathrm{P}, \mathrm{K}, \mathrm{Na}$ and $\mathrm{Ca}$ lines enabled this differentiation. NanosecondLIBS did not perform as well as fs-LIBS in this regards, but the authors concluded that the sonicated and autoclaved bacteria were still differentiable from live bacteria, as Multari et al. observed above. Malenfant et al. confirmed this observation [70] by showing that spectra from autoclaved $E$. coli possessed detectable and reproducible alterations compared to spectra from viable $E$. coli. These autoclaved specimens were still classified with $100 \%$ accuracy with live E.coli specimens in a four genus DFA which discriminated $E$. coli from S. epidermidis, M. smegmatis, and $P$. aeuruginosa.

Farid et al. have explored this idea further by utilizing LIBS to show the difference between viable and non-viable cells due to graphene-oxide exposure [79]. E. coli and S. aureus specimens were ablated with nanosecond laser pulses after exposure to graphene-oxide at various concentrations and decreases in the measured elemental intensities were observed in both genera of bacteria. Importantly, these authors point demonstrate the use of LIBS as a tool not merely for bacterial identification or classification, but as a rapid and relatively inexpensive all-optical spectroscopic technique for probing membrane composition to ultimately determine the anti-bacterial mechanism of the graphene-oxide material. This is one of the many examples of experiments which could be performed with this "atomic microbiology" technique, which are generally complementary to the more developed suite of "molecular microbiology" tools and tests.

\subsubsection{Environmental testing gas}

The effect of the bath gas environment on LIBS-based bacterial classification has not been extensively studied. The vast majority of LIBS researchers continue to perform experiments in either an air atmosphere, for convenience, or in a noble-gas environment to enhance plasma emissions. Rehse et al. examined this by ablating $P$. aeruginosa in both air and argon and observed that the increase in LIBS 
emission allowed a reduction in the number of laser pulses required, advantageous for most bacterial experiments where the amount of sample can be almost vanishingly small [61]. In addition, the enhancement in phosphorus emission, particularly from lines in the wavelength range of 203 to $256 \mathrm{~nm}$ was seen to significantly enhance discrimination ability, as phosphorus is a key element in the phospholipid bilayer membranes present in many bacteria. The use of sequential argon and helium testing on the same specimen was investigated by Rehse et al. who observed a reduction in scatter and an enhancement in discrimination between two strains of $E$. coli and a single strain of $S$. mutans when the spectra from specimens ablated in both environment were combined to create a pseudo-spectrum as opposed to the discrimination obtained in either gas independently [60].

Farooq et al. compared and contrasted bacterial LIBS performance in air, argon, and helium environments [80]. Specimens of E. coli and Micrococcus luteus mounted on a glass slide were ablated by a $1064 \mathrm{~nm}$ laser. The authors noted differences in the emission intensities from the important lines of carbon at $193 \mathrm{~nm}$ and $247 \mathrm{~nm}$ and the hydrogen alpha line at $656 \mathrm{~nm}$. Intriguingly, emission lines from nickel were observed in one of their test specimens, but only when measured in the argon environment, indicating that small but significant elemental differences may not be observed when ablated in an ambient air environment.

\subsection{Interferents}

Due to the low analyte mass or volume inherent in the ablation of a small number of bacterial cells, it is probable that many LIBS spectra may be "contaminated" by emission from other elements which may or may not be present in the bacteria. Such elements may be introduced to the plasma from the ablation substrate, from contamination of the substrate, or from contamination of the sample before it is mounted upon the substrate. Such contaminants may be organic or inorganic and are referred to as interferents. When present in large numbers or in high concentrations, the LIBS emission from interferents can mask the desired bacterial LIBS emission, precluding detection or identification.

In 2007, Xu et al. performed initial experiments to investigate whether fs-LIBS could be used to detect and differentiate some very similar agricultural-activity related bioaerosols, including barley, corn, and wheat grain dust when ablated at standoff distances up to $4 \mathrm{~m}$ [81]. No bacteria were tested. Ratios of measured LIBS intensities of $\mathrm{Mg}, \mathrm{Si}, \mathrm{Al}$, and $\mathrm{Mn}$ allowed an efficient discrimination of these bioaerosol types. Since $\mathrm{Si}, \mathrm{Al}$, and $\mathrm{Mn}$ are not traditionally observed in bacterial LIBS plasmas, these bioaerosol interferents should be differentiable from bacterial spectra. No chemometric analysis was attempted on these data. In addition, nonlinear fluorescence of fragments induced by the femtosecond filaments was observed and could be used to discriminate organic interferents from other carbon-containing inorganic interferents.

Gottfried investigated an extensive list of interferents and their influence on the detection of $B$. antrharis spores and E. coli [37]. Interfering lines in the plasma emission were created by ablation on aluminum, steel, and polycarbonate substrates. As well, potential environmental interferents included dolomitic limestone and ovalbumin. Other interferents which would possess spectra similar to bacteria which were included in the test included Luria broth, phosphate-buffered saline with $1 \%$ bovine serum albumin, and $1 \mathrm{M}$ chloroform among others. All spectra were obtained in isolation and a list of observed emission lines was created. Using ratios of observed emission lines, PLS-DA models were constructed. Full spectrum models were also created, but the author observed that such spectra also contained emission from the substrate and the atmosphere which allowed an inaccurate classification based on matrix effects, rather than real elemental differences. While these full-spectrum models gave the best 
overall performance (with the caveat just noted,) the intensity/ratio models were very useful for differentiating samples with fewer spectral features, specifically the $E$. coli bacteria.

Cisewski et al. utilized an SVM classification to discriminate powders of Bacillus spores from a large variety of interferents (referred to by the authors as confusants) [57]. Interferents used were too numerous to list here but included items such as flour, backing soda, chalk, laundry detergent, ibuprofen, baby powder, and other similar powders all pressed into pellets by a 20 ton press. The SVM classification utilizing several other standard statistical technique to improve performance including outlier rejection provided quite good classification accuracy with prediction errors between $0.0 \%$ and 3.4\%. Unfortunately only pure substances were tested in this study, and no bacterial spore specimens were ever mixed with any of the interferents to provide a true simulation of sample contamination, limiting the relevance of these conclusions.

Mohaidat et al. performed the first simulation of a clinical diagnostic test by demonstrating that biomolecule and elemental interferents present in a urine specimen did not in any way negatively effect the classification of $S$. epidermidis cells harvested from a nominally sterile urine environment [64]. Classification was performed using a DFA library constructed from spectra obtained from three species of Staphylococcus, none of which had ever been exposed to the sterile urine environment. No attempt was made to identify the type of interferents present in such a clinical biofluid.

By ablating bacterial samples directly on various agar media such as blood agar, cysteine heart agar and an unknown agar, Multari et al. have shown that given the careful construction of medium-specific PLS algorithms, the interferents present in the plasma due to the inevitable ablation of some of the agar medium upon which the bacterial cells are mounted do not restrict the overall classification ability [38]. Such a result had been shown earlier by Diedrich et al. who discriminated strains of $E$. coli from each other regardless of the growth medium used (a TSA plate or a TSB liquid nutrient medium) [58] and by Rehse et al. who demonstrated $100 \%$ discrimination of $E$. coli from $P$. aeruginosa when specimens were cultured on TSA, blood agar, and MacConkey agar nutrient plates [59]. None of these specimens was ablated directly on those various growth media, but the samples were not washed extensively prior to LIBS testing.

\subsection{Stand-off / remote testing}

In one of the earliest demonstrations of what the authors referred to as remote detection and differentiation, $\mathrm{Xu}$ et al. showed that fs-LIBS $(800 \mathrm{~nm}$ Ti-sapphire system, $45 \mathrm{fs}$ pulse duration operating at $10 \mathrm{~Hz}$ ) could be used to detect and differentiate similar agricultural activity related bioaerosols, at standoff distances up to $4 \mathrm{~m}$ [81]. The beam was focused in air using a $1 \mathrm{~m}$ lens onto compressed dust samples and emission was collected by a $30 \mathrm{~cm}$ diameter aluminum mirror located $4.7 \mathrm{~m}$ away from the LIBS spark. High signal-to-noise spectra were collected from the fs-LIBS plasma in this configuration, and as mentioned earlier fluorescence from $\mathrm{CN}$ and $\mathrm{C}_{2}$ molecular bands generated in this process were used to discriminate organic interferents. No bacteria were tested in this paper.

In a subsequent expansion of this idea, Chin et al. explored the use of "filament-induced" fluorescence and filament-induced breakdown spectroscopy (FIBS) to identify remote targets [82]. The authors refer to this as remote-FIBS or R-FIBS. In this study, filament-induced spectra were acquired from aluminum samples located $50 \mathrm{~m}$ and $32 \mathrm{~m}$ away from the detection system in a remote LIDAR configuration and also from simulated biological agents such as egg white, yeast, and grain. Again no bacteria were tested. 
Using an alternate approach, Gottfried et al. developed a double-pulse standoff LIBS (ST-LIBS) system which could detect a variety of hazardous target materials at tens of meters distance [33]. In this configuration, two nanosecond $1064 \mathrm{~nm}$ laser pulses were delivered by a commercial $35.56 \mathrm{~cm}$ (14 in.) Schmidt-Cassegrain telescope to targets at $20 \mathrm{~m}$. LIBS emission was collected by the same telescope. Specimens of the anthrax surrogate $B$. subtilis var. niger (also referred to as B. globigii) and the mold Alternia alternata were applied directly to a double-sided sticky tape mounting medium. No evidence of the mounting tape was observed in the collected spectra. Single-shot spectra obtained in this way possessed good signal-to-noise and included strong elemental and molecular lines, but many elemental lines expected by the authors, such as $\mathrm{Ba}, \mathrm{Fe}, \mathrm{Li}, \mathrm{Mn}, \mathrm{Sc}, \mathrm{Si}$, and $\mathrm{Sr}$, were not observed. It is worth noting that these lines are not observed in a majority of the bacterial studies referenced in this review. A significant conclusion of this work was that the use of two optimally timed pulses provided dramatically enhanced performance over single pulse LIBS at these distances.

In a subsequent study, Gottfried et al. demonstrated the discrimination of this $B$. subtilis from the biological interferents ovalbumin, $A$. alternata, and $B$. thuringiensis with only $2 \%$ false negatives and $0 \%$ false positives [68]. Spectra were collected with the same apparatus at $20 \mathrm{~m}$ and analyzed utilizing both a PLS-DA and a linear correlation. Typical results for this analysis are shown in Figure 9, which shows representative single-shot spectra acquired with this apparatus, as well as showing the results of a PLSDA performed on one of the micro-organisms and one of the interferents. The authors noted that for explosive detection, standoff distances up to 100 meters may be possible, but for biologicals and pathogens, the relative weakness of the essential phosphorus emission may limit the utility of this approach to $20 \mathrm{~m}$ or less.

\subsection{LIBS combined with alternate optical modalities for bacteriological discrimination}

As evidenced clearly in the remote experiments described earlier, the all-optical nature of the LIBS measurement suggests that the combination of LIBS with another laser-based optical spectroscopic technique is expected to enhance the discrimination ability of the technique and lower the limits of detection. This idea was clearly considered by Beddows and Telle who envisioned the combination of LIBS with either Raman spectroscopy, laser-induced fluorescence, or both for bioaerosol identification [28]. They proposed utilizing an initial low intensity laser for bioaerosol particle sizing and triggering, where the particle size could also add diagnostic information. In their conception, a second laser pulse of suitable wavelength chosen to limit the intrinsic fluorescence would illuminate the sample to generate Raman emission. Additionally, a third ultraviolet pulse could be used subsequently to obtain a UV-fluorescence spectrum. Finally, a fourth nanosecond laser pulse would be used to destructively interrogate the sample by generating a LIBS spectrum. No such experiments were conducted, but a proposed prototype was discussed.

As already mentioned, the complementary information provided by analysis of the filament-induced fluorescence, particular molecular emission from $\mathrm{CN}$ and $\mathrm{C}_{2}$ provided valuable diagnostic information when fs-LIBS or R-FIBS is conducted [81,82]. By measuring the decay profiles of this fluorescence, differences in native $\mathrm{CN}$ and $\mathrm{C}_{2}$ bonds present in biological specimens from those due to recombination with atmospheric constituents can be observed, which was first noted by Baudelet et al. [47,49].

Rather than study the time dependence of fluorescence, Saari et al. collected the full fluorescence spectrum from $320 \mathrm{~nm}$ to $820 \mathrm{~nm}$ after excitation with a $355 \mathrm{~nm}$ tripled Nd:YAG pulse [35]. A 355-nm filter was used to block out the excitation wavelength and significant and repeated differences were observed in the spectra collected from the fungal spores Aspergillus versicolor and Penicillium 
brevicompactum and the bacterial spore B. aureus. By using an electro-dynamic balance, essentially background-free data were obtained from bioaerosols generated from water suspensions and the combined LIBS/LIF measurements enabled a high-sensitivity repeatable classification of the bioaerosols.

Figure 9. (a) Single shot spectra acquired from (top to bottom) $B$. globigii, ova, $B$. thuringiensis, and mold acquired using the double pulse standoff LIBS system shown in (b) at a 20 m standoff distance. Samples were prepared by spreading several milligrams of powders on double-sided tape. (c) The predictions scores for (top to bottom) B. globigii and Arizona road dust based on a PLS-DA model showing $100 \%$ classification of the B. globigii spectra and almost similar performance for the road dust. In this figure, known spectra used to build the model are identified above the prediction line and to the left of the figure (model sample index) while the unknown spectra are to the right of the figure (test sample index) and are identified by virtue of being above the prediction line. Adapted from references [33 and 68].

(a)

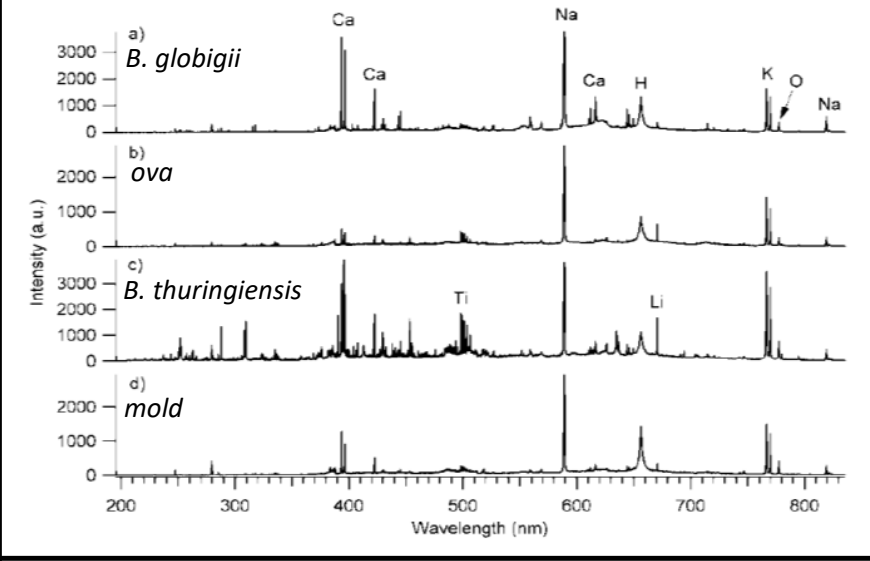

(b)
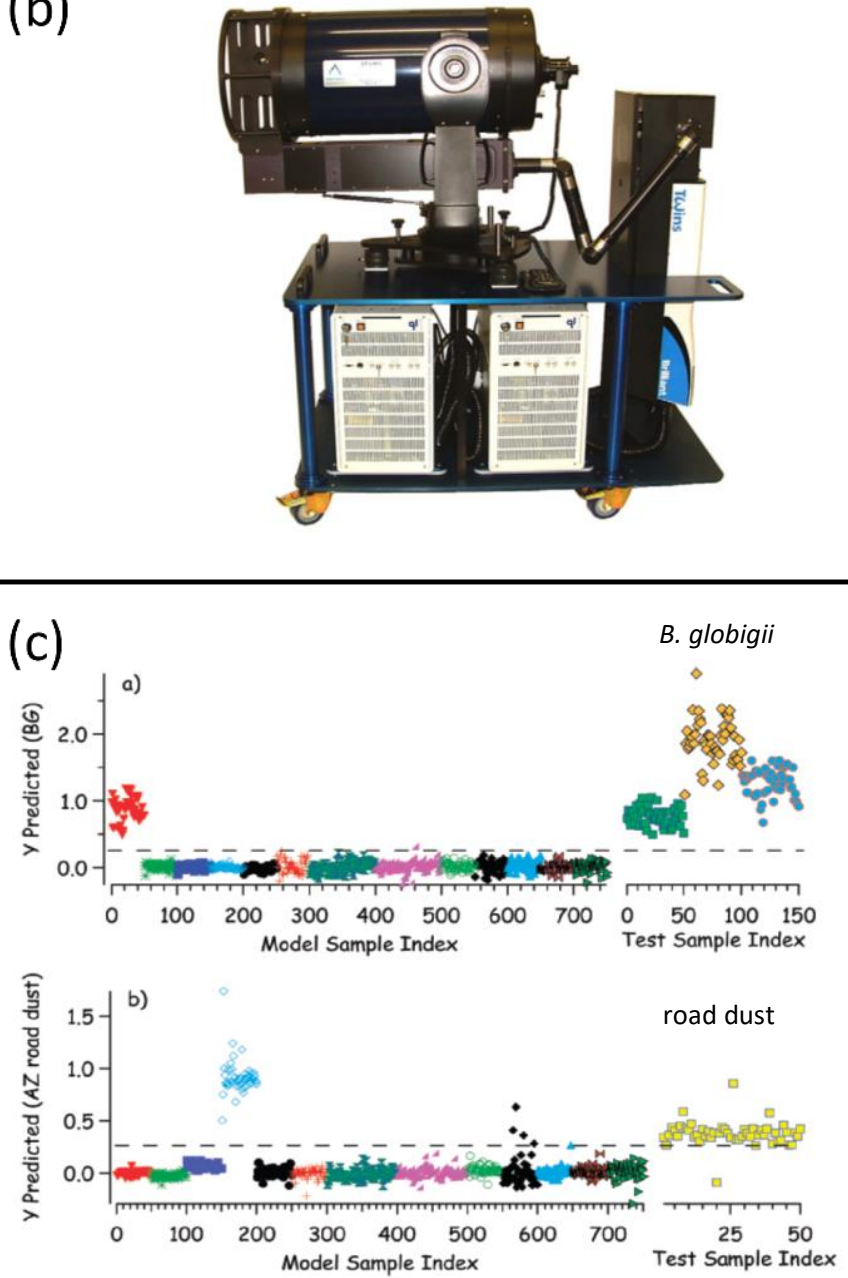
It is perhaps most obvious that the combination of elemental LIBS information with molecular Raman information affords the greatest possibility for increasing classification performance when classifying bacteria. Non-enhanced Raman spectroscopy has also demonstrated bacterial classification and discrimination at the strain level, even before techniques such as surface-enhancement or tipenhancement are introduced (see, for example, Hamasha et al. [83].) It is hardly surprising that the addition of this modality should enhance LIBS-based discrimination, yet no consensus on how such "data fusion" is to be performed exists. Prochazka et al. merged their data by simply appending the LIBS spectrum from $200 \mathrm{~nm}$ to $900 \mathrm{~nm}$ with the Raman spectrum obtained from $632.551 \mathrm{~cm}^{-1}-1723.820$ $\mathrm{cm}^{-1}$ to generate a pseudo-spectrum from $200 \mathrm{~nm}$ to $1407.02 \mathrm{~nm}$ [56]. A PCA was used to discriminate these spectra, and the Raman part of the spectrum was found to contain more variance than the LIBS part, as can be seen in Figure 10. Representative spectra from both modalities is also provided for reference. The LIBS portion of the spectrum however played a critical role for PC1, which always contains the most significant variance.

Liao et al. introduced silver nanoparticles into a suspension of $S$. aureus to take advantage of the wellknown surface-enhancement afforded by the nanoparticles [51]. The authors utilized a custom-built LIBS/Raman apparatus utilizing $1064 \mathrm{~nm}$ ns LIBS pulses and a $532 \mathrm{~nm}$ cw laser for Raman excitation. The silver content of the nanoparticles was readily apparent in the LIBS spectra acquired with this apparatus. Interestingly, while the authors demonstrated a PCA-derived classification of $E$. coli and S. aureus and utilized the LIBS spectra to calculate a limit of quantification, they do not appear to have fused the data, or used the two modalities together in any way to improve overall classification. Thus the utility of coming the two modalities was not made evident. As noted, more studies need to be conducted to determine how best to fuse the data acquired with the two techniques. 

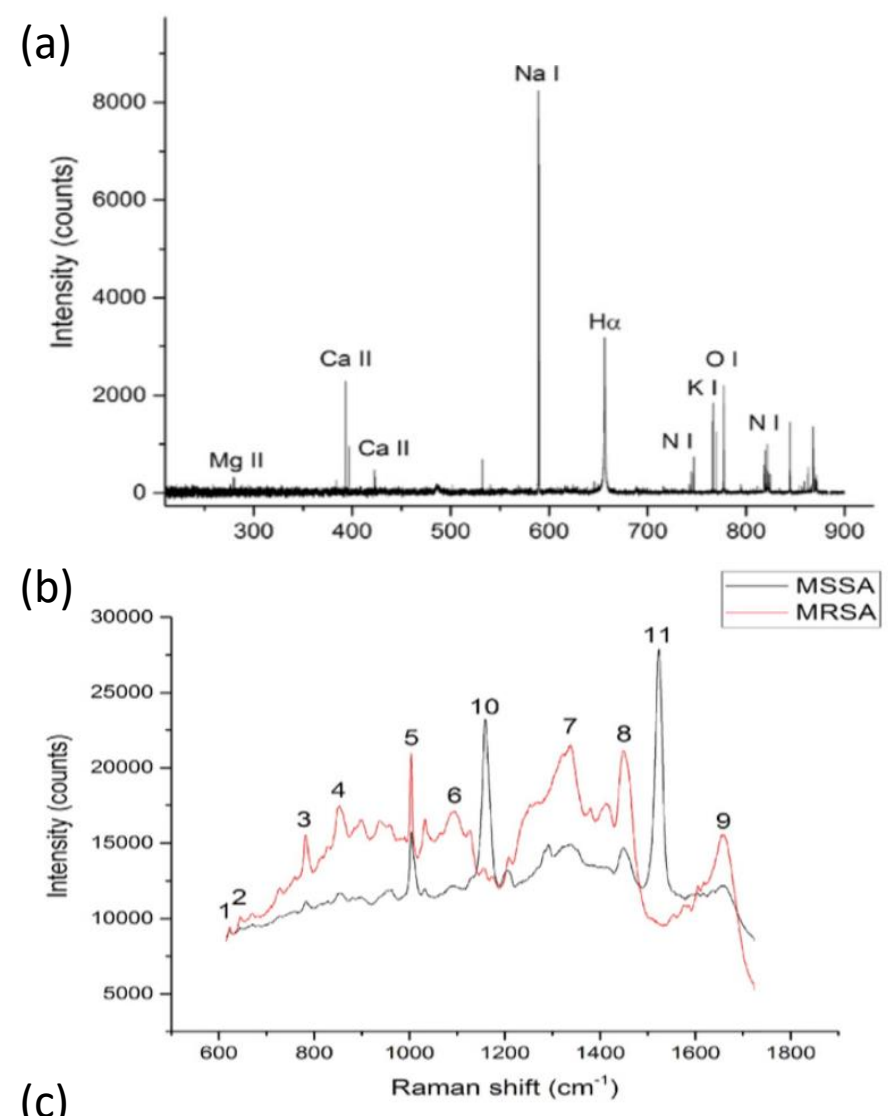

(c)
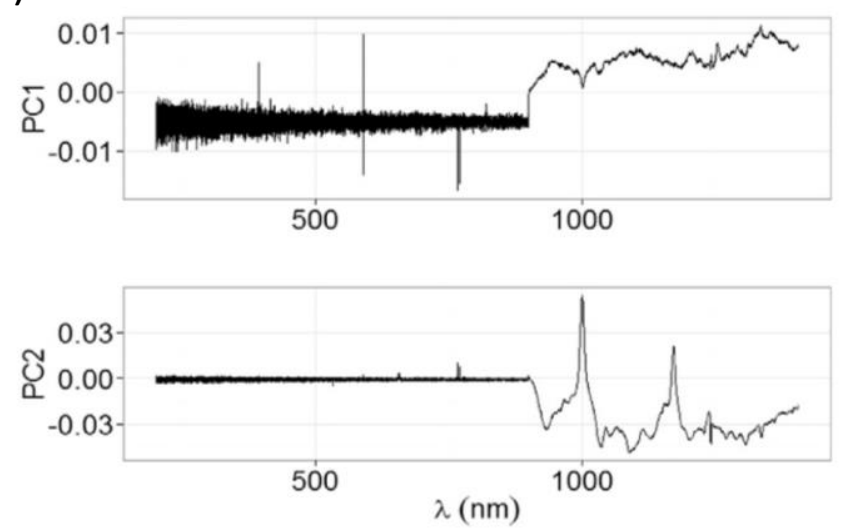

Figure 10. (a) A typical LIBS spectrum of $S$. aureus (methicillin resistant strain) acquired from the surface of a growth medium plate. (b) A typical Raman spectrum acquired from the same specimen (in red). (c) The loading of PC1 (top) and PC2 (bottom) for the fused LIBS/Raman data. The LIBS data comprises the loadings up to $900 \mathrm{~nm}$, demonstrating that the Raman data accounts for the largest contribution to the variance of the data. However several emission lines in the LIBS data show loading contributions of equal intensity in PC1. Reprinted from reference [56] with permission from Elsevier. 


\section{Summary and Outlook}

\subsection{Summary}

Over the course of approximately 15 years, the use of LIBS for rapid bacterial classification or detection has been improved from initial proof-of-concept experiments to sophisticated experiments that clearly demonstrate clinical utility. A summary of the most significant conclusions described in this review are provided in Table 1.

\section{Table 1}

A summary of the most significant conclusions described in this work.

A LIBS spectrum bacterial classification utilizing an appropriately constructed library can provide a sensitive and specific test (high rates of true positives, low rates of false positives) to rapidly identify an unknown bacterial specimen or to differentiate between possible identifications.

This LIBS spectral fingerprint:

- Is robust, reliable, and persistent through time (multiple tests spanning years on the same strains of bacteria). Minor changes in experimental conditions do not alter sample identifications.

- Is capable of strain-level discrimination.

- Is relatively growth-medium independent.

- Is easily differentiable from other types of bio-organisms (molds, fungi, yeast).

- Is independent of the state of growth of the cells (how "old" the bacteria are).

- Is relatively independent of whether the bacteria are live or dead (or inactivated by UV light). Some differences are observed in killed bacterial cells, particularly when fs-LIBS is used.

- Can be used for discrimination even when other types of bacteria or interferents are present (mixed samples, residual growth media, ablated substrates, other biotypes).

- Can be obtained from urine specimens.

- Can be obtained from even a single bacterial cell.

- Can be obtained at standoff distances up to $20 \mathrm{~m}$.

- Can be fused with data from other optical modalities for enhanced discrimination.

- Can be differentiated using a large variety of chemometric techniques (no single technique demonstrates greatly improved performance.)

- Can be acquired with nanosecond pulses of any wavelength as well as femtosecond pulses.

The wide variety of bacteria which have been tested with LIBS offers evidence of the utility of the approach. Because the technique is not biochemically based, a single apparatus can identify any and all of the bacteria that are ablated in the LIBS plasma. A summary of all the bacteria that have ever been tested in a LIBS apparatus, as well as an identification of the substrate upon which this analysis was performed, the state of the bacteria, the specific chemometric routine used in identification, and the type of laser utilized in the test are presented in table 2. 
Table 2

A summary of all the bacterial species/strains tested with LIBS.

\begin{tabular}{|c|c|c|c|c|}
\hline Micro-organism & Reference & Form & $\begin{array}{l}\text { Chemometric } \\
\text { utilized }\end{array}$ & $\begin{array}{l}\text { Laser } \\
\text { wavelength }^{\mathrm{a}}\end{array}$ \\
\hline $\begin{array}{l}\text { Acinetobacter baumannii ATCC } \\
\text { BAA-1789 }\end{array}$ & 66 & Colony on blood agar & PCA/PLS1 & 1064 \\
\hline Acinetobacter baylyi & 48 & $\begin{array}{l}\text { Pellet, freeze-dried } \\
\text { powder }\end{array}$ & $\begin{array}{l}\text { Hyperspace } \\
\text { projection of } \\
\text { trace elements }\end{array}$ & $810(\mathrm{fs})$ \\
\hline 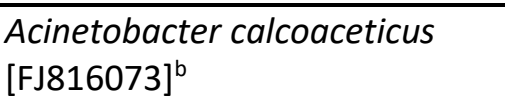 & 71 & Colony on glass slide & PCA/PLS-RA & $800(\mathrm{fs})$ \\
\hline Arhodomonas sp. [EU308280] & 71 & Colony on glass slide & PCA/PLS-RA & 800 (fs) \\
\hline Bacillus anthracis var. Sterne & 44 & $\begin{array}{l}\text { Thin lawnc on nylon } \\
\text { filter }\end{array}$ & None & 1064 \\
\hline Bacillus anthracis var. Sterne & 38 & $\begin{array}{l}\text { Thin lawn on agar, } \\
\text { glass slide }\end{array}$ & PCA/PLS1 & 1064 \\
\hline Bacillus atrophaeous & 41 & $\begin{array}{l}\text { Spore, aerosol } \\
\text { stream }\end{array}$ & None & 1064 \\
\hline Bacillus atrophaeous & 52,37 & $\begin{array}{l}\text { Dried film on Al disk, } \\
\text { steel disk, } \\
\text { polycarbonate disk }\end{array}$ & $\begin{array}{l}\text { NN, } \\
\text { MLSRA,PLS-DA }\end{array}$ & 1064 \\
\hline Bacillus atrophaeous & 57 & $\begin{array}{l}\text { Pellet, freeze-dried } \\
\text { powder }\end{array}$ & SVM & 1064 \\
\hline Bacillus aureus & 35 & Spore, EDB trap & None & 355 \\
\hline Bacillus cereus 6E1 & 29,32 & $\begin{array}{l}\text { Thin lawn on silver } \\
\text { membrane filter }\end{array}$ & $\begin{array}{l}\text { PCA, linear } \\
\text { correlation, } \\
\text { and SIMCA }\end{array}$ & 1064 \\
\hline Bacillus cereus ATCC 14603 & 57 & $\begin{array}{l}\text { Pellet, freeze-dried } \\
\text { powder }\end{array}$ & SVM & 1064 \\
\hline Bacillus globigii $^{\mathrm{d}}$ BG-1 & 39,40 & $\begin{array}{l}\text { Pellet, freeze-dried } \\
\text { powder }\end{array}$ & None & 1064 \\
\hline Bacillus globigii BG-1 & 40 & $\begin{array}{l}\text { Spore, aerosol } \\
\text { stream }\end{array}$ & None & 1064 \\
\hline Bacillus globigii BG-2 & 39,40 & $\begin{array}{l}\text { Pellet, freeze-dried } \\
\text { powder }\end{array}$ & None & 1064 \\
\hline Bacillus globigii BG-2 & 40 & $\begin{array}{l}\text { Spore, aerosol } \\
\text { stream }\end{array}$ & None & 1064 \\
\hline Bacillus globigii var. niger & $29,42,32$ & $\begin{array}{l}\text { Thin lawn on silver } \\
\text { membrane filter }\end{array}$ & $\begin{array}{l}\text { PCA, linear } \\
\text { correlation, } \\
\text { and SIMCA }\end{array}$ & 1064 \\
\hline Bacillus globigii var. niger & 30 & $\begin{array}{l}\text { Continually } \\
\text { refreshed dense } \\
\text { aerosol cloud (from } \\
\text { powder) and aerosol } \\
\text { stream }\end{array}$ & PCA & 1064 \\
\hline
\end{tabular}




\begin{tabular}{|c|c|c|c|c|}
\hline Bacillus globigii var. niger & 35,68 & $\begin{array}{l}\text { Powder on double- } \\
\text { sided sticky tape }\end{array}$ & $\begin{array}{l}\text { No, linear } \\
\text { correlation, } \\
\text { PCA, PLS-DA }\end{array}$ & $1064 \times 2(D P)$ \\
\hline Bacillus globigii 168 & 43 & $\begin{array}{l}\text { Colony (wet) on LB } \\
\text { medium }\end{array}$ & None & 532 \\
\hline Bacillus globigii & 47 & $\begin{array}{l}\text { Thin film lawn on } \\
\text { cellulose nitrate } \\
\text { membrane filter }\end{array}$ & None & $\begin{array}{l}810(\mathrm{fs}) \\
1064\end{array}$ \\
\hline Bacillus globigii & 48 & $\begin{array}{l}\text { Pellet, freeze-dried } \\
\text { powder }\end{array}$ & $\begin{array}{l}\text { Hyperspace } \\
\text { projection of } \\
\text { trace elements }\end{array}$ & 810 (fs) \\
\hline Bacillus globigii & 31 & $\begin{array}{l}\text { Dried powder on } \\
\text { solid substrate }\end{array}$ & $\begin{array}{l}\text { PCA, HCA, } \\
\text { PCA+LDA }\end{array}$ & 1064 \\
\hline Bacillus globigii ATCC 23857 & 66 & Colony on blood agar & PCA/PLS1 & 1064 \\
\hline Bacillus megaterium QM B1551 & 43 & $\begin{array}{l}\text { Colony (wet) on LB } \\
\text { medium }\end{array}$ & None & 532 \\
\hline Bacillus megaterium PV361 & 43 & $\begin{array}{l}\text { Colony (wet) on LB } \\
\text { medium }\end{array}$ & None & 532 \\
\hline $\begin{array}{l}\text { Bacillus stearothermophilus } \\
\text { ATCC } 12979\end{array}$ & 57 & $\begin{array}{l}\text { Pellet, freeze-dried } \\
\text { powder }\end{array}$ & SVM & 1064 \\
\hline Bacillus thurengensis & 39,40 & $\begin{array}{l}\text { Pellet, freeze-dried } \\
\text { powder }\end{array}$ & None & 1064 \\
\hline $\begin{array}{l}\text { Bacillus thurengensis var. } \\
\text { kurstaki }\end{array}$ & 29,32 & $\begin{array}{l}\text { Thin lawn on silver } \\
\text { membrane filter }\end{array}$ & $\begin{array}{l}\text { PCA, linear } \\
\text { correlation, } \\
\text { and SIMCA }\end{array}$ & 1064 \\
\hline $\begin{array}{l}\text { Bacillus thurengensis var. } \\
\text { kurstaki }\end{array}$ & 44 & $\begin{array}{l}\text { Thin lawn on nylon } \\
\text { filter }\end{array}$ & None & 1064 \\
\hline Bacillus thurengensis T34 & 43 & $\begin{array}{l}\text { Colony (wet) on LB } \\
\text { medium }\end{array}$ & None & 532 \\
\hline $\begin{array}{l}\text { Bacillus thuringiensis ATCC } \\
51912\end{array}$ & 57 & $\begin{array}{l}\text { Pellet, freeze-dried } \\
\text { powder }\end{array}$ & SVM & 1064 \\
\hline Bacillus sp. [GQ392044] & 71 & Colony on glass slide & PCA/PLS-RA & 800 (fs) \\
\hline Bacillus sp. [GQ226038] & 71 & Colony on glass slide & PCA/PLS-RA & 800 (fs) \\
\hline Bacillus sp. [HM026606] & 71 & Colony on glass slide & PCA/PLS-RA & 800 (fs) \\
\hline $\begin{array}{l}\text { Enterobacter cloacae } \\
\text { [FJ194527] }\end{array}$ & 71 & Colony on glass slide & PCA/PLS-RA & $800(\mathrm{fs})$ \\
\hline $\begin{array}{l}\text { Enterobacter cloacae ATCC } \\
13047\end{array}$ & 64,67 & $\begin{array}{l}\text { Thin lawn on } \\
\text { nutrient-free agar }\end{array}$ & DFA, PLS-DA & 1064 \\
\hline Enterobacter sp. [CP000653] & 71 & Colony on glass slide & PCA/PLS-RA & $800(\mathrm{fs})$ \\
\hline Enterobacter sp. [GU586319] & 71 & Colony on glass slide & PCA/PLS-RA & 800 (fs) \\
\hline Enterobacter sp.[FJ194525] & 71 & Colony on glass slide & PCA/PLS-RA & $800(\mathrm{fs})$ \\
\hline Erwinia chrysanthemi & 48 & $\begin{array}{l}\text { Pellet, freeze-dried } \\
\text { powder }\end{array}$ & $\begin{array}{l}\text { Hyperspace } \\
\text { projection of } \\
\text { trace elements } \\
\end{array}$ & 810 (fs) \\
\hline Escherichia coli & 39,40 & $\begin{array}{l}\text { Pellet, freeze-dried } \\
\text { powder }\end{array}$ & None & 1064 \\
\hline
\end{tabular}




\begin{tabular}{|c|c|c|c|c|}
\hline Escherichia coli & 47,49 & $\begin{array}{l}\text { Thin lawn on } \\
\text { cellulose nitrate } \\
\text { membrane filter }\end{array}$ & None & $\begin{array}{l}810(\mathrm{fs}) \\
1064\end{array}$ \\
\hline Escherichia coli & 48 & $\begin{array}{l}\text { Pellet, freeze-dried } \\
\text { powder }\end{array}$ & $\begin{array}{l}\text { Hyperspace } \\
\text { projection of } \\
\text { trace elements }\end{array}$ & 810 (fs) \\
\hline Escherichia coli IHII/pHT315 & 43 & $\begin{array}{l}\text { Colony (wet) on LB } \\
\text { medium }\end{array}$ & None & 532 \\
\hline $\begin{array}{l}\text { Escherichia coli K-12 (AB), Hfr- } \\
\text { K12, HF4714, C (Nino C), } \\
\text { O157:H7, ATCC } 25922\end{array}$ & $\begin{array}{l}34,58,60 \\
62,63,64 \\
67\end{array}$ & $\begin{array}{l}\text { Thin lawn on } \\
\text { nutrient-free agar }\end{array}$ & DFA, PLS-DA & 1064 \\
\hline Escherichia coli & 70 & $\begin{array}{l}\text { Thin lawn on } \\
\text { cellulose nitrate } \\
\text { membrane filter }\end{array}$ & DFA, PLS-DA & 1064 \\
\hline $\begin{array}{l}\text { Escherichia coli O157:H7 ATCC } \\
4389\end{array}$ & 72 & $\begin{array}{l}\text { Thin lawn on ground } \\
\text { beef, bologna, } \\
\text { chicken, milk, } \\
\text { eggshell, lettuce, } \\
\text { drain, cutting board, } \\
\text { swab }\end{array}$ & PCA/PLS1 & 1064 \\
\hline Escherichia coli & 75 & $\begin{array}{l}\text { Thin lawn on filter } \\
\text { paper }\end{array}$ & None & 1064 \\
\hline Escherichia coli & 76 & $\begin{array}{l}\text { Thin lawn on filter } \\
\text { paper and sausage }\end{array}$ & None & 1064 \\
\hline Escherichia coli DH5 $\alpha$ & 65 & Freeze-dried powder & PCA,PLS2 & 1064 \\
\hline Escherichia coli & 77 & $\begin{array}{l}\text { Thin lawn on silicon } \\
\text { wafer }\end{array}$ & DFA & 266 \\
\hline Escherichia coli OV2 & 53 & $\begin{array}{l}\text { Colony on LB, } \\
\text { MacConkey, Brucella } \\
\text { agar medium }\end{array}$ & NN & 1064 \\
\hline Escherichia coli ATCC 15597 & 37 & $\begin{array}{l}\text { Dried film on Al disk, } \\
\text { steel disk, } \\
\text { polycarbonate disk }\end{array}$ & PLS-DA & 1064 \\
\hline Escherichia coli K12 ATCC 10798 & 66 & Colony on blood agar & PCA/PLS1 & 1064 \\
\hline Escherichia coli & 80 & $\begin{array}{l}\text { Thin lawn on glass } \\
\text { slide }\end{array}$ & None & 1064 \\
\hline $\begin{array}{l}\text { Escherichia coli MC6-RP11, } \\
\text { QCB1 }\end{array}$ & 54 & Colony on LB agar & NN & 1064 \\
\hline Escherichia coli K12 & 74 & $\begin{array}{l}\text { Thin lawn on } \\
\text { plexiglass }\end{array}$ & PCA/SIMCA & $\begin{array}{l}1064,775 \\
\text { (fs) }\end{array}$ \\
\hline Escherichia coli & 55 & Unknown & $\begin{array}{l}\text { K-means } \\
\text { classifier and } \\
\text { NN }\end{array}$ & 1064 \\
\hline Escherichia coli CCM 3954 & 56 & Colony on MH agar & $\begin{array}{l}\text { PCA, Self- } \\
\text { Organizing } \\
\text { Maps (NN) }\end{array}$ & 532 \\
\hline
\end{tabular}




\begin{tabular}{|c|c|c|c|c|}
\hline $\begin{array}{l}\text { Escherichia coli K12, ATCC } \\
25922\end{array}$ & 51 & $\begin{array}{l}\text { Thin lawn on silicon } \\
\text { wafer }\end{array}$ & PCA, HCA & 1064 \\
\hline Escherichia coli ATCC 25254 & 79 & $\begin{array}{l}\text { Thin lawn on } \\
\text { plexiglass substrate }\end{array}$ & None & 1064 \\
\hline $\begin{array}{l}\text { Francisella tularensis vaccine } \\
\text { strain }\end{array}$ & 38 & $\begin{array}{l}\text { Thin lawn on agar, } \\
\text { glass slide }\end{array}$ & PCA/PLS1 & 1064 \\
\hline $\begin{array}{l}\text { Klebsiella pneumoniae ATCC } \\
13882\end{array}$ & 66 & Colony on blood agar & PCA/PLS1 & 1064 \\
\hline $\begin{array}{l}\text { Klebsiella pneumonia K21P, } \\
\text { K18P, K17P, K16R, K11CM, } \\
\text { K11P, K7P,K6P, K3C, K2P }\end{array}$ & 54 & Colony on LB agar & NN & 1064 \\
\hline Listeria innocua & 73 & $\begin{array}{l}\text { Pellet, freeze-dried } \\
\text { powder }\end{array}$ & $\begin{array}{l}\text { PCA, } \\
\text { Mahalanobis } \\
\text { discriminant } \\
\text { analysis (MDA) }\end{array}$ & 266 \\
\hline $\begin{array}{l}\text { Methylophilus methylotrophus } \\
\text { [AB193724] }\end{array}$ & 71 & Colony on glass slide & PCA/PLS-RA & 800 (fs) \\
\hline Methylophilus sp. [AY436800] & 71 & Colony on glass slide & PCA/PLS-RA & 800 (fs) \\
\hline Methylophilus sp. [EU375653] & 71 & Colony on glass slide & PCA/PLS-RA & 800 (fs) \\
\hline Methylophilus sp. [GQ175365] & 71 & Colony on glass slide & PCA/PLS-RA & 800 (fs) \\
\hline Micrococcus luteus & 80 & $\begin{array}{l}\text { Thin lawn on glass } \\
\text { slide }\end{array}$ & None & 1064 \\
\hline $\begin{array}{l}\text { Mycobacterium smegmatis } \\
\text { wild-type, TE, TA }\end{array}$ & $62,63,64,67$ & $\begin{array}{l}\text { Thin lawn on } \\
\text { nutrient-free agar }\end{array}$ & DFA, PLS-DA & 1064 \\
\hline Mycobacterium smegmatis & 70 & $\begin{array}{l}\text { Thin lawn on } \\
\text { cellulose nitrate } \\
\text { membrane filter }\end{array}$ & DFA, PLS-DA & 1064 \\
\hline Paenibacillus sp. [AY728023] & 71 & Colony on glass slide & PCA/PLS-RA & 800 (fs) \\
\hline $\begin{array}{l}\text { Pantoea agglomerans } \\
\text { [FJ611822] }\end{array}$ & 71 & Colony on glass slide & PCA/PLS-RA & 800 (fs) \\
\hline Proteus mirabilis & 39,40 & $\begin{array}{l}\text { Pellet, freeze-dried } \\
\text { powder }\end{array}$ & None & 1064 \\
\hline Pseudomonas aeruginosa M841 & 53 & $\begin{array}{l}\text { Colony on LB, } \\
\text { MacConkey, Brucella } \\
\text { agar medium }\end{array}$ & NN & 1064 \\
\hline Pseudomonas aeruginosa & 59 & $\begin{array}{l}\text { Thin lawn on } \\
\text { nutrient-free agar }\end{array}$ & DFA & 1064 \\
\hline Pseudomonas aeruginosa & 70 & $\begin{array}{l}\text { Thin lawn on } \\
\text { cellulose nitrate } \\
\text { membrane filter }\end{array}$ & DFA, PLS-DA & 1064 \\
\hline $\begin{array}{l}\text { Pseudomonas aeruginosa } \\
\text { [HM036358] }\end{array}$ & 71 & Colony on glass slide & PCA/PLS-RA & 800 (fs) \\
\hline $\begin{array}{l}\text { Pseudomonas aeruginosa ATCC } \\
33580\end{array}$ & 66 & Colony on blood agar & PCA/PLS1 & 1064 \\
\hline $\begin{array}{l}\text { Pseudomonas aeruginosa PA1- } \\
\text { PA19 }\end{array}$ & 54 & Colony on LB agar & NN & 1064 \\
\hline
\end{tabular}




\begin{tabular}{|c|c|c|c|c|}
\hline Pseudomonas putida & 73 & $\begin{array}{l}\text { Pellet, freeze-dried } \\
\text { powder }\end{array}$ & $\begin{array}{l}\text { PCA, } \\
\text { Mahalanobis } \\
\text { discriminant } \\
\text { analysis (MDA) }\end{array}$ & 266 \\
\hline $\begin{array}{l}\text { Salmonella enterica serovar } \\
\text { Typhimurium }^{\text {e }}\end{array}$ & 77 & $\begin{array}{l}\text { Thin lawn on silicon } \\
\text { wafer }\end{array}$ & DFA & 266 \\
\hline Salmonella enterica ATCC 8324 & 72 & $\begin{array}{l}\text { Thin lawn on ground } \\
\text { beef, bologna, } \\
\text { chicken, milk, } \\
\text { eggshell, lettuce, } \\
\text { drain, cutting board, } \\
\text { swab }\end{array}$ & PCA/PLS1 & 1064 \\
\hline $\begin{array}{l}\text { Salmonella pollorum 1JVC, } \\
1 / 1 \mathrm{Km}, 2 / 1 \mathrm{Km}\end{array}$ & 54 & Colony on LB agar & NN & 1064 \\
\hline $\begin{array}{l}\text { Salmonella salamae } 2 \mathrm{JVC} \text {, } \\
1 / 2 \mathrm{Km}, 2 / 2 \mathrm{Km}\end{array}$ & 54 & Colony on LB agar & NN & 1064 \\
\hline $\begin{array}{l}\text { Salmonella typhymurium } \\
\text { LB5010 }\end{array}$ & 53 & $\begin{array}{l}\text { Colony on LB, } \\
\text { MacConkey, Bucella } \\
\text { agar medium }\end{array}$ & $\begin{array}{l}\text { Neural } \\
\text { networks }\end{array}$ & 1064 \\
\hline $\begin{array}{l}\text { Salmonella typhimurium SL- } \\
1344,1 / 22 \mathrm{Km}, 2 / 22 \mathrm{Km}\end{array}$ & 54 & Colony on LB agar & NN & 1064 \\
\hline Salmonella typhymurium & 73 & $\begin{array}{l}\text { Pellet, freeze-dried } \\
\text { powder }\end{array}$ & $\begin{array}{l}\text { PCA, } \\
\text { Mahalanobis } \\
\text { discriminant } \\
\text { analysis (MDA) }\end{array}$ & 266 \\
\hline Salmonella typhymurium & 51 & $\begin{array}{l}\text { Thin lawn on silicon } \\
\text { wafer }\end{array}$ & PCA, HCA & 1064 \\
\hline Shewanella oneidensis & 48 & $\begin{array}{l}\text { Pellet, freeze-dried } \\
\text { powder }\end{array}$ & $\begin{array}{l}\text { Hyperspace } \\
\text { projection of } \\
\text { trace elements }\end{array}$ & $810(\mathrm{fs})$ \\
\hline Staphylococcus aureus & 39,40 & $\begin{array}{l}\text { Pellet, freeze-dried } \\
\text { powder }\end{array}$ & None & 1064 \\
\hline $\begin{array}{l}\text { Staphylococcus aureus MRSA: } \\
\text { LP9, MM61, MM66, MM66-4 }\end{array}$ & 65 & Freeze-dried powder & PCA,PLS2 & 1064 \\
\hline Staphylococcus aureus & $62,64,67$ & $\begin{array}{l}\text { Thin lawn on } \\
\text { nutrient-free agar }\end{array}$ & DFA,PLS-DA & 1064 \\
\hline Staphylococcus aureus & 77 & $\begin{array}{l}\text { Thin lawn on silicon } \\
\text { wafer }\end{array}$ & DFA & 266 \\
\hline $\begin{array}{l}\text { Staphylococcus aureus SH1000, } \\
\text { SH1000-1, RN4220, RN4220-fail, } \\
\text { MRSA: LP9, MM61, MM66, } \\
\text { MM66-4 }\end{array}$ & 66 & Colony on blood agar & PCA/PLS1 & 1064 \\
\hline Staphylococcus aureus & 73 & $\begin{array}{l}\text { Pellet, freeze-dried } \\
\text { powder }\end{array}$ & $\begin{array}{l}\text { PCA, } \\
\text { Mahalanobis } \\
\text { discriminant } \\
\text { analysis (MDA) }\end{array}$ & 266 \\
\hline
\end{tabular}




\begin{tabular}{|c|c|c|c|c|}
\hline Staphylococcus aureus & 55 & Unknown & $\begin{array}{l}\text { K-means } \\
\text { classifier and } \\
\text { NN }\end{array}$ & 1064 \\
\hline Staphylococcus aureus & 51 & $\begin{array}{l}\text { Thin lawn on silicon } \\
\text { wafer }\end{array}$ & PCA, HCA & 1064 \\
\hline Staphylococcus aureus CCM & & & PCA, Self- & \\
\hline $\begin{array}{l}\text { 4223, CCM } 4750 \text { (MRSA), CCM } \\
3953 \text { (MSSA) }\end{array}$ & 56 & Colony on $\mathrm{MH}$ agar & $\begin{array}{l}\text { Organizing } \\
\text { Maps (NN) }\end{array}$ & 532 \\
\hline $\begin{array}{l}\text { Staphylococcus aureus ATCC } \\
25923\end{array}$ & 79 & $\begin{array}{l}\text { Thin lawn on } \\
\text { plexiglass substrate }\end{array}$ & None & 1064 \\
\hline Staphylococcus epidermidis & 64 & $\begin{array}{l}\text { Thin lawn on } \\
\text { nutrient-free agar }\end{array}$ & DFA,PLS-DA & 1064 \\
\hline Staphylococcus epidermidis & 70 & $\begin{array}{l}\text { Thin lawn on } \\
\text { cellulose nitrate } \\
\text { membrane filter }\end{array}$ & DFA, PLS-DA & 1064 \\
\hline $\begin{array}{l}\text { Staphylococcus } \\
\text { pseudointermedius }\end{array}$ & 56 & Colony on $\mathrm{MH}$ agar & $\begin{array}{l}\text { PCA, Self- } \\
\text { Organizing } \\
\text { Maps (NN) } \\
\end{array}$ & 532 \\
\hline Staphylococcus saprophyticus & $62,64,67$ & $\begin{array}{l}\text { Thin lawn on } \\
\text { nutrient-free agar }\end{array}$ & DFA, PLS-DA & 1064 \\
\hline Staphylococcus sciuri & 56 & Colony on $\mathrm{MH}$ agar & $\begin{array}{l}\text { PCA, Self- } \\
\text { Organizing } \\
\text { Maps (NN) } \\
\end{array}$ & 532 \\
\hline Streptococcus mutans & $60,62,64,67$ & $\begin{array}{l}\text { Thin lawn on } \\
\text { nutrient-free agar }\end{array}$ & DFA, PLS-DA & 1064 \\
\hline Streptococcus viridans & $62,63,64,67$ & $\begin{array}{l}\text { Thin lawn on } \\
\text { nutrient-free agar }\end{array}$ & DFA,PLS-DA & 1064 \\
\hline
\end{tabular}

aall lasers have ns pulse duration unless otherwise noted

${ }^{b}$ Genbank accession number

'Lawn usually denotes a liquid suspension deposited on a substrate then allowed to dry for a variable amount of time to form a thin, dry or semi-dry film. A colony means a growth accumulation region not in suspension or dispersed in a liquid.

${ }^{\mathrm{d}}$ Bacillus globigii is also known as Bacillus subtilis

eS. enterica serovar Typhimurium is commonly referred to by its serovar identification only as $S$.

typhimurium or by its more proper taxonomic identification, $S$. Typhimurium

\subsection{Outlook}

The body of literature summarized here makes clear that the use of a LIBS-based diagnostic to identify unknown bacteria in a specimen, and to differentiate those bacteria from the normal non-pathogenic flora that are to be found ubiquitously in nature is eminently feasible. While the fundamentals have been well-established there are several important questions that yet remain to be answered which should provide research impetus for years to come.

The single most important advance that could be initiated is the use of a LIBS-diagnostic in a clinical environment such as a clinic or hospital microbiology laboratory. The majority, if not all, of the experiments performed here were done in a research setting within either a university, institute, or 
company. And while clinical microbiologists and pathologists have been involved, the extent of these collaborations has usually been to provide LIBS practitioners, who are usually not microbiologists, with credible and realistic samples to test. This is not the same as performing experiments on actual samples obtained in a clinical environment, either human or otherwise (perhaps the use in a veterinary environment may occur first due to the lowered regulatory thresholds.) In any case, tests should be performed on actual clinical specimens that have been obtained in duplicate by medical personnel using the standard collection protocols and these specimens should be then tested with both LIBS and via whatever modality is in use at that institution so that a true comparison of the accuracy of the LIBS test against other gold-standard methods can be performed. In addition to the accuracy of the results, this would also allow for the first time an analysis of the workflow burden that the introduction of a new test would introduce to a clinical setting as well as illuminate any savings in time that would be gained. Of course, it is obvious that the results of any such tests could in no way be used to direct patient treatment, as this is a completely unregulated and unapproved (as of yet) testing modality. But it would be a crucial first step toward initiating trials that could lead to regulatory approval.

The lowest number of cells that can be detected with the LIBS diagnostic has been measured in a variety of experiments (as detailed in section 3.6) in a research setting, and has been shown to be quite low. What remains to be demonstrated is whether the number of cells obtained in a clinical specimen is adequate for sensitive and specific identification and whether it is consistently distinguishable from "negatives," or specimens containing no bacteria. As negative samples are routinely acquired in clinical environments which now require an ever-increasing number of tests to err on the side of caution, the rate of false-positives on negative samples will need to be exceedingly low for the test to be accepted by clinical microbiologists.

Another important area of concern is the testing of "mixed samples." A mixed sample is one in which it would be typical to find numerous types of different bacteria, most of which are non-pathogenic and do not need to be treated. One example of this would be a swab of the inside of the mouth, another is the gastrointestinal tract. The only investigations of this were discussed in section 3.6. Because the LIBS spectra of bacteria do not possess great diversity and almost all spectra contain the same atomic and ionic emission lines, the extent to which a pathogenic microorganism could be identified in the presence of a background of non-pathogenic flora is unknown. The utility of a LIBS test on specimens derived from such a mixture of bacteria utilizing the techniques currently available cannot at this time be evaluated.

A final area of interest showing significant promise is the use of a LIBS test not as a tool for microbiological identification in a clinical setting, but rather as a rapid and convenient assay of cellular elemental composition. It is this use of the technique, referred to here as atomic microbiology, which could provide research microbiologists with a new laboratory tool. The alteration of cellular chemistry due to environmental or pharmacological influences is an area of microbiological study, and it has been shown that the LIBS assay is an effective technique for monitoring changes in this biochemistry as discussed in section 3.3. The development of a convenient benchtop instrument easily usable by nonexperts and a suitable mounting protocol for specimens to be tested with such an instrument would allow the introduction of the LIBS technique into such studies. The presence of such a tool in a microbiology laboratory might then initiate new research areas which could make use of the ready availability of the high-throughput, fairly straightforward and inexpensive assay.

So it should be clear that the next step in the introduction of a LIBS-based diagnostic into clinical medicine or microbiology research is the continuing inclusion of experts in these areas of science into 
teams containing LIBS experts and the increasing exportation of LIBS technology from the LIBS laboratories into those other settings. Continued cooperation between LIBS practitioners and the ultimate end-users of the technology is the most certain way to insure the early adoption of the technology into those fields.

\section{Acknowledgement}

The author would like to gratefully acknowledge the financial support of a Natural Sciences and Engineering Research Council of Canada Discovery grant and RTI equipment grant as well as a Canada Foundation for Innovation - Ontario Innovation Fund infrastructure grant. In addition, portions of the work discussed in this review were supported by both the University of Windsor's Outstanding Scholars program and NSERC USRA scholarships as well as a MITACS Globalink Research Internship. 


\section{References}

[1] D.A. Cremers, L.J. Radziemski (Eds.), Handbook of Laser-Induced Breakdown Spectroscopy. 1st ed. John Wiley \& Sons Ltd., Chichester, 2006.

[2] A.W. Miziolek, V. Palleschi, I. Schechter (Eds.), Laser Induced Breakdown Spectroscopy. 1st ed., Cambridge University Press, Cambridge, 2006.

[3] J. Singh, S. Thakur (Eds.), Laser-Induced Breakdown Spectroscopy. 1st ed., Elsevier, Amsterdam, 2007.

[4] S. Musazzi, U. Perini (Eds.) Laser-Induced Breakdown Spectroscopy: Theory and Applications, Springer, Berlin, 2014. https://doi.org/10.1007/978-3-642-45085-3 17

[5] F.J. Fortes, J. Moros, P. Lucena, L.M. Cabalin, J.J. Laserna, Laser-induced breakdown spectroscopy, Anal. Chem. 85 (2013) 640-669. https://doi.org/10.1021/ac303220r

[6] D.W. Hahn, N. Omenetto, Laser-induced breakdown spectroscopy (LIBS), Part I: Review of basic diagnostics and plasma-particle interactions: still-challenging issues within the analytical plasma community, Appl. Spectrosc. 64 (2010) 335A-366A. https://doi.org/10.1366/000370210793561691

[7] D.A. Cremers, R.C. Chinni, Laser-induced breakdown spectroscopy-capabilities and limitations, Appl. Spectrosc. Rev. 44 (2009) 457-506. https://doi.org/10.1080/05704920903058755

[8] C. Aragón, J.A. Aguilera, Characterization of laser induced plasmas by optical emission spectroscopy: A review of experiments and methods. Spectrochim. Acta B 63 (2008) 893-916. https://doi.org/10.1016/i.sab.2008.05.010

[9] E. Tognoni, V. Palleschi, M. Corsi, G. Cristoforetti, Quantitative micro-analysis by laser-induced breakdown spectroscopy: a review of the experimental approaches, Spectrochim. Acta B 57 (2002) 1115-1130. https://doi.org/10.1016/S0584-8547(02)00053-8

[10] J.L. Gottfried, F.C. De Lucia Jr., C.A. Munson, A.W. Miziolek, Laser-induced breakdown spectroscopy for detection of explosives residues: a review of recent advances, challenges, and future prospects, Anal. Bioanal. Chem. 395 (2009) 283-300. https://doi.org/10.1007/s00216-009-2802-0

[11] G.S. Senesi, M. Senesi, Laser-induced breakdown spectroscopy (LIBS) to measure quantitatively soil carbon with emphasis on soil organic carbon. A review, Anal. Chim. Acta 938 (2016) 7-17.

https://doi.org/10.1016/i.aca.2016.07.039

[12] C. Li, C.-L.Feng, H.Y. Oderji, G.-N. Luo, H.-B. Ding, Review of LIBS application in nuclear fusion technology, Front. Phys. 11 (2016) 114214-1-16. https://doi.org/10.1007/s11467-016-0606-1

[13] D. Santos Jr., L.C. Nunes, G.G.i Arantes de Carvalho, M. da Silva Gomes, P.F. de Souza, F. de Oliveira Leme, L. G.C. dos Santos, F.J. Krug, Laser-induced breakdown spectroscopy for analysis of plant materials: A review, Spectrochim. Acta B 71-72 (2012) 3-13. https://doi.org/10.1016/j.sab.2012.05.005

[14] M. Markiewicz-Keszycka, X. Cama-Moncunill, M.P. Casado-Gavalda, Y. Dixit, R. Cama-Moncunill, P.J. Cullen, C. Sullivan, Laser-induced breakdown spectroscopy (LIBS) for food analysis: A Review, Trends Food Sci. Technol. 65 (2017) 80-93. http://doi.org/10.1016/j.tifs.2017.05.005

[15] A. Giakoumaki, K. Melessanaki, D. Anglos, Laser-induced breakdown spectroscopy (LIBS) in archaeological science-applications and prospects, Anal. Bioanal. Chem. 387 (2007) 749-760. https://doi.org/10.1007/s00216006-0908-1

[16] R.S. Harmon, R.E. Russo, R.R. Hark, Applications of laser-induced breakdown spectroscopy for geochemical and environmental analysis: A comprehensive review, Spectrochim Acta B 87 (2013) 11-26.

https://dx.doi.org/10.1016/j.sab.2013.05.017

[17] R. Gaudiuso, M. Dell'Aglio, O. De Pascale, G.S. Senesi, A. De Giacomo, Laser induced breakdown spectroscopy for elemental analysis in environmental, cultural heritage and space applications: A review of methods and results, Sensors 10 (2010) 7434-7468. https://doi.org/10.3390/s100807434 
[18] H.H. Telle, O. Samek, Biomedical applications of LIBS, in: A.W. Miziolek, V. Palleschi, I. Schechter (Eds.), Laser Induced Breakdown Spectroscopy. 1st ed., Cambridge University Press, Cambridge, 2006. pp. 282-313.

[19] V.K. Singh, A.K. Rai, Prospects for laser-induced breakdown spectroscopy for biomedical applications: a review, Lasers Med. Sci. 26 (2011) 673-687. https://doi.org/10.1007/s10103-011-0921-2.

[20] S.J. Rehse, H. Salimnia, A.W. Miziolek, Laser-induced breakdown spectroscopy (LIBS): an overview of recent progress and future potential for biomedical applications., J. Med. Eng. Technol. 36 (2012) 77-89.

https://doi.org/10.3109/03091902.2011.645946.

[21] A.K. Pathak, R.Kumar, V.K. Singh, R. Agrawal, S. Rai, A.K. Rai, Assessment of LIBS for spectrochemical analysis: a review, Appl. Spectrosc. Rev. 47 (2012) 14-40. https://doi.org/10.1080/05704928.2011.622327.

[22] S.J. Rehse, Biomedical applications of LIBS, in: S. Musazzi, U. Perini (Eds.) Laser-Induced Breakdown Spectroscopy: Theory and Applications, Springer, Berlin, 2014, 457-488. https://doi.org/10.1007/978-3-64245085-3 17

[23] O. Lazcka, F.J. Del Campo, F.X. Muño, Pathogen detection: A perspective of traditional methods and biosensors, Biosens. Bioelectron. 22 (2007) 1205-1217. https://doi.org/10.1016/i.bios.2006.06.036

[24] E.C. Alocilja, S.M. Radke, Industry review: Market analysis of biosensors for food safety, Biosens. Bioelectron. 18 (2003) 841-846.

[25] J.H.T. Luong, K.B. Male, J.D. Glennon, Biosensor technology: Technology push versus market pull. Biotechnology Advances 26 (2008) 492-500. https://doi.org/10.1016/i.biotechadv.2008.05.007.

[26] P.S. Mead, L. Slutsker, V. Dietz, L.F. McCaig, J.S. Bresce, C. Shapiro, P.M. Griffin, R.V. Tauxe,. Food-Related Illness and Death in the United States, Centers for Disease Control and Prevention, Atlanta, 2000.

[27] G.E. Cohn, Systems and Technologies for Clinical Diagnostics and Drug Discovery, SPIE Proceedings Vol. 3259. The International Society for Optical Engineering, Bellingham, 1998.

[28] D.C.S. Beddows, H.H. Telle, Prospects of real-time single-particle biological aerosol analysis: A comparison between laser-induced breakdown spectroscopy and aerosol time-of-flight mass spectrometry, Spectrochim. Acta B 60, (2005) 1040-1059. https://doi.org/10.1016/i.sab.2005.05.018

[29] A.C. Samuels, F.C. DeLucia Jr, K.L. McNesby, A.W. Miziolek, Laser-induced breakdown spectroscopy of bacterial spores, molds, pollens, and protein: initial studies of discrimination potential, Appl. Opt. 42 (2003) 62056209. https://doi.org/10.1364/AO.42.006205

[30] J.D. Hybl, G.A. Lithgow, S.G. Buckley, Laser-induced breakdown spectroscopy detection and classification of biological aerosols, Appl. Spect. 57 (2003) 1207-1215.

[31] D.W. Merdes, J.M. Suhan, J.M. Keay, D.M. Hadka, W.R. Bradley, The investigation of laser-induced breakdown spectroscopy for detection of biological contaminants on surfaces, Spectroscopy 22 (2007) 28-38.

[32] C.A. Munson, F.C. DeLucia, Jr., T. Piehler, K.L. McNesby, A.W. Miziolek, Investigation of statistics strategies for improving the discriminating power of laser-induced breakdown spectroscopy for chemical and biological warfare agent simulants, Spectrochim. Acta B 60 (2005) 1217-1224. https://doi.org/10.1016/i.sab.2005.05.017

[33] J.L. Gottfried, F.C. De Lucia Jr., C.A. Munson, A.W. Miziolek, Double-pulse standoff laser-induced breakdown spectroscopy for versatile hazardous materials detection, Spectrochim. Acta B 62 (2007) 1405-1411.

https://doi.org/10.1016/i.sab.2007.10.039

[34] J. Diedrich, S.J. Rehse, S. Palchaudhuri, Escherichia coli identification and strain discrimination using nanosecond laser-induced breakdown spectroscopy, Appl. Phys. Lett. 90 (2007) 163901 1-3.

https://doi.org/10.1063/1.2723659

[35] S. Saari, S. Järvinen, T. Reponen, J. Mensah-Attipoe, P. Pasanen, J. Toivonen, J. Keskinen, Identification of single microbial particles using electro-dynamic balance assisted laser-induced breakdown and fluorescence spectroscopy, Aerosol Sci. Technol. 50 (2016) 126-132. https://doi.org/10.1080/02786826.2015.1134764 
[36] S. Manzoor, L. Ugena, J. Tornero-Lopéz, H. Martín, M. Molina, J.J. Camacho, J.O. Cáceres, Laser-induced breakdown spectroscopy for the discrimination of Candida strains, Talanta 155 (2016) 101-106.

https://doi.org/10.1016/i.talanta.2016.04.030

[37] J.L. Gottfried, Discrimination of biological and chemical threat simulants in residue mixtures on multiple substrates, Anal. Bioanal. Chem. 400 (2011) 3289-3301. https://doi.org/10.1007/s00216-011-4746-4

[38] R.A. Multari, D.A. Cremers, M.L. Bostian, Use of laser-induced breakdown spectroscopy for the differentiation of pathogens and viruses on substrates, Appl. Opt. 51 (2012) B57-B64. https://doi.org/10.1364/AO.51.000B57

[39] S. Morel, N. Leone, P. Adam, J. Amouroux, Detection of bacteria by time-resolved laser-induced breakdown spectroscopy, Appl. Opt. 42 (2003) 6184-6191. https://doi.org/10.1364/AO.42.006184

[40] N. Leone, G. D'Arthur, P. Adam, J. Amouroux. Detection of bacterial deposits and bioaerosals by time-resolved laser-induced breakdown spectroscopy (TRELIBS). High Technol. Plasma Process. 8 (2004) 1-22.

https://doi.org/10.1615/HighTempMatProc.v8.i1.10

[41] P.B. Dixon, D.W. Hahn, Feasibility of detection and identification of individual bioaerosols using laser-induced breakdown spectroscopy, Anal. Chem. 77 (2005) 631-638. https://doi.org/10.1021/ac048838i

[42] F.C. DeLucia Jr, A.C. Samuels, R.S. Harmon, R.A. Walter, K.L. McNesby, A. LaPointe, R.J. Winkel Jr, A.W. Miziolek, Laser-induced breakdown spectroscopy (LIBS): a promising versatile chemical sensor technology for hazardous material detection, IEEE Sens. Jour. 50 (2005) 681-689. https://doi.org/10.1109/JSEN.2005.848151

[43] T. Kim, Z.G. Specht, P.S. Vary, C.T. Lin, Spectral fingerprints of bacterial strains by laser-induced breakdown spectroscopy, J. Phys. Chem. B 108 (2004) 5477-5482. https://doi.org/10.1021/jp031269i

[44] J.L. Kiel, E.A. Holwitt, J.E. Parker, J. Vivekananda, V. Franz, M.A. Sloan, A.W. Miziolek, F.C. DeLucia Jr, C.A. Munson, Y.D. Mattley, Specific biological agent taggants, Proc. SPIE 5795 (2005) 39-45.

https://doi.org/10.1117/12.597640

[45] A. Assion, M. Wollenhaupt, L. Haag, F. Mayorov, C. Sarpe-Tudoran, M. Winter, U. Kutschera, T. Baumert, Femtosecond laser-induced breakdown spectrometry for $\mathrm{Ca2}+$ analysis of samples with high spatial resolution, Applied Physics B, 77 (2003) 391-397. https://doi.org/10.1007/s00340-003-1262-z

[46] L. Guyon, M. Baudelet, J. Yu, J. Wolf, T. Amodeo, E. Frejafon, and P. Laloi, Laser-Induced Breakdown Spectroscopy Analysis of Bacteria: What Femtosecond Lasers Make Possible, in 15th International Conference on Ultrafast Phenomena, OSA Technical Digest Series (CD) (Optical Society of America, 2006), paper MH10. https://doi.org/10.1364/UP.2006.MH10

[47] M. Baudelet, L. Guyon, J. Yu, J.-P. Wolf, T. Amodeo, E. Frejafon, P. Laloi, Femtosecond time-resolved laserinduced breakdown spectroscopy for detection and identification of bacteria: A comparison to the nanosecond regime, J. Appl. Phys. 99 (2006) 084701. https://doi.org/10.1063/1.2187107

[48] M. Baudelet, J. Yu, M. Bossu, J. Jovelet, J.-P. Wolf, T. Amodeo, E. Frejafon, P. Laloi, Discrimination of microbiological samples using femtosecond laser-induced breakdown spectroscopy, Appl. Phys. Lett. 89 (2006) 163903. https://doi.org/10.1063/1.2361270

[49] M. Baudelet, L. Guyon, J. Yu, J.-P. Wolf, T. Amodeo, E. Frejafon, P. Laloi, Spectral signature of native CN bonds for bacterium detection and identification using femtosecond laser-induced breakdown spectroscopy, Appl. Phys. Lett. 88 (2006) 06391. https://doi.org/10.1063/1.2170437

[50] M. Baudelet, M. Boueri, J. Yu, S.S. Mao, V. Piscitelli, X. Mao, R.E. Russo, Time-resolved ultraviolet laser-induced breakdown spectroscopy for organic material analysis, Spectrochim. Acta B 62 (2007) 1329-1334.

https://doi.org/10.1016/i.sab.2007.10.043

[51] W. Liao, Q. Lin, S. Xie, Y. He, Y. Tian, Y. Duan, A novel strategy for rapid detection of bacteria in water by the combination of three-dimensional surface-enhanced Raman scattering (3D SERS) and laser induced breakdown spectroscopy (LIBS), Anal. Chim. Acta 1043 (2018) 1-8. https://doi.org/10.1016/i.aca.2018.06.058 
[52] E.G. Snyder, C.A. Munson, J.L. Gottfried, F.C. De Lucia Jr., B. Gullett, A.W. Miziolek, Laser-induced breakdown spectroscopy for the classification of unknown powders, Appl. Opt. 47 (2008) G80-G87.

https://doi.org/10.1007/s00216-009-2802-0

[53] D. Marcos-Martinez, J.A. Ayala, R.C. Izquierdo-Hornillos, F.J. Manuel de Villena, J.O. Caceres, Identification and discrimination of bacterial strains by laser induced breakdown spectroscopy and neural networks, Talanta 84

(2011) 730-737. https://doi.org/10.1016/j.talanta.2011.01.069

[54] S. Manzoor, S. Moncayo, F. Navarro-Villoslada, J.A. Ayala, R. Izquierdo-Hornillos, F.J. Manuel de Villena, J.O. Caceres, Rapid identification and discrimination of bacterial strains by laser-induced breakdown spectroscopy and neural networks, Talanta 121 (2014) 65-70. https://doi.org/10.1016/j.talanta.2013.12.057

[55] F.G. Rendon Sauz, T. Flores Reyes, R. Ortega Izaguirre, A.K. Frias, A.E. Villarreal, L. Ponce, Applications of laserinduced breakdown spectroscopy in the identification of bacteria, in: A. Martınez-Garcla et al. (eds.), Emerging Challenges for Experimental Mechanics in Energy and Environmental Applications, Proceedings of the 5th International Symposium on Experimental Mechanics and 9th Symposium on Optics in Industry (ISEM-SOI), Springer, Cham, Switzerland, 2015, pp. 29-33. https://doi.org/10.1007/978-3-319-28513-9 4

[56] D. Prochazka, M. Mazura, O. Samek, K. Rebrošová, P. Pořízka, J. Klus, P. Prochazková, J. Novotný, K. Novotný, J. Kaiser, Combination of laser-induced breakdown spectroscopy and Raman spectroscopy for multivariate classification of bacteria, Spectrochim. Acta B 139 (2018) 6-12. https://doi.org/10.1016/j.sab.2017.11.004

[57] J. Cisewski, E. Snyder, J. Hannig, L. Oudejans, Support vector machine classification of suspect powders using laser-induced breakdown spectroscopy (LIBS) spectral data, J. Chemometrics 26 (2012) 143-149.

https://doi.org/10.1002/cem.2422

[58] J. Diedrich, S.J. Rehse, S. Palchaudhuri, Pathogenic Escherichia coli strain discrimination using laser-induced breakdown spectroscopy, J. Appl. Phys. 102 (2007) 014702 1-8. https://doi.org/10.1063/1.2752784

[59] S.J. Rehse, J. Diedrich, S. Palchaudhuri, Identification and discrimination of Pseudomonas aeruginosa bacteria grown in blood and bile by laser-induced breakdown spectroscopy, Spectrochim. Acta B 62 (2007) 1169-1176. https://doi.org/10.1016/i.sab.2007.07.008

[60] S.J. Rehse, Q.I. Mohaidat, The effect of sequential dual-gas testing on a LIBS-based discrimination of brass and bacteria, Spectrochim. Acta B 64 (2009) 1020-1027. https://doi.org/10.1016/j.sab.2009.07.012

[61] S.J. Rehse, N. Jeyasingham, J. Diedrich, S. Palchaudhuri, A membrane basis for bacterial identification and discrimination using laser-induced break-down spectroscopy, J. Appl. Phys. 105 (2009) 102034 1-13. https://doi.org/10.1063/1.3116141

[62] S.J. Rehse, Q.I. Mohaidat, S. Palchaudhuri, Towards the clinical application of laser-induced breakdown spectroscopy for rapid pathogen diagnosis: the effect of mixed cultures and sample dilution on bacterial identification, Appl. Opt. 49 (2010) C27-C35. https://doi.org/10.1364/AO.49.000C27

[63] Q. Mohaidat, S. Palchaudhuri, S.J. Rehse, The effect of bacterial environmental and metabolic stresses on a LIBS-based identification of Escherichia coli and Streptococcus viridans. Appl. Spectrosc. 65 (2011) 386-392. https://doi.org/10.1366/10-06178

[64] Q.I. Mohaidat, K. Sheikh, S. Palchaudhuri, S.J. Rehse, Pathogen identification with laser-induced breakdown spectroscopy: the effect of bacterial and biofluid specimen contamination, Appl. Opt. 51 (2012) B99-B107. https://doi.org/10.1364/AO.51.000B99

[65] R. Multari, D.A. Cremers, J.M. Dupre, J.E. Gustafson, The use of laser-induced breakdown spectroscopy for distinguishing between bacterial pathogen species and strains, Appl. Spectrosc. 64 (2010) 750-759.

https://doi.org/10.1366/000370210791666183

[66] R.A. Multari, D.A. Cremers, M.L. Bostian, J.M. Durpr, J.E. Gustafson, Proof of principle for a real-time pathogen isolation media diagnostic: the use of laser-induced breakdown spectroscopy to discriminate bacterial pathogens and antimicrobial-resistant Staphylococcus aureus strains grown on blood agar, J. Pathog. 2013 (2013), 898106 111. https://doi.org/10.1155/2013/898106 
[67] R.A. Putnam, Q.I. Mohaidat, A. Daabous, S.J. Rehse, A comparison of multivariate analysis techniques and variable selection strategies in a laser-induced breakdown spectroscopy bacterial classification, Spectrochim. Acta B 87 (2013) 161-167. https://doi.org/10.1016/i.sab.2013.05.014

[68] J.L. Gottfried, F.C. De Lucia Jr., C.A. Munson, A.W. Miziolek, Standoff detection of chemical and biological threats using laser-induced breakdown spectroscopy, Appl. Spectrosc. 62 (2008) 353-36.

https://doi.org/10.1366/000370208784046759

[69] J.L. Gottfried, F.C. DeLucia Jr., A.W. Miziolek, Discrimination of explosive residues on organic and inorganic substrates using laser-induced breakdown spectroscopy, J. Anal. At. Spectrom. 24 (2009) 288-296.

https://doi.org/10.1039/B818481J

[70] D.J. Malenfant, D.J. Gillies, S.J. Rehse, Bacterial suspensions deposited on microbiological filter material for rapid laser-induced breakdown spectroscopy identification, Appl. Spectrosc. 70 (2016) 485-493.

https://doi.org/10.1177/0003702815626673

[71] D.E. Lewis, J. Martinez, C.A. Akpovo, L. Johnson, A. Chauhan, M.D. Edington, Discrimination of bacteria from Jamaican bauxite soils using laser-induced breakdown spectroscopy, Anal. Bioanal. Chem. 401 (2011) 2225-2236. https://doi.org/10.1007/s00216-011-5274-y

[72] R.A. Multari, D.A. Cremers, J.M. Dupre, J.E. Gustafson, Detection of biological contaminants on foods and food surfaces using laser-induced breakdown spectroscopy (LIBS), J. Agric. Food Chem. 61 (2013) 8687-8694.

https://doi.org/10.1021/jf4029317

[73] G.R. Gamble, B. Park, S.-C. Yoon, K.C. Lawrence, Effect of sample preparation on the discrimination of bacterial isolates cultured in liquid nutrient media using laser-induced breakdown spectroscopy (LIBS), Appl. Spectrosc. 70 (2016) 494-504. https://doi.org/10.1177/0003702815626679

[74] P. Sivakumar, A. Fernandez-Bravo, L. Taleh, J.F. Biddle, N. Melikechi, Detection and classification of live and dead Escherichia coli by laser-induced breakdown spectroscopy, Astrobiology 15 (2015) 144-153.

https://doi.org/10.1089/ast.2014.1181

[75] M. Yao, J. Lin, M. Liu, Q. Li, Z. Lei and L. Huang, Identification of Escherichia coli by laser-induced breakdown spectroscopy, 2010 3rd International Conference on Biomedical Engineering and Informatics (Yantai, 2010) 302305. https://doi.org/10.1109/BMEl.2010.5639492

[76] X. Yuan, Y. Mingyin, L. Muhua, Application of LIBS in Detection of Escherichia coli in Sausages, 2011 International Conference on Computer, Electrical, and Systems Sciences, and Engineering CESSE 2011) (Wuhan, 2011) 379-382.

[77] C. Barnett, C. Bell, K. Vig, C.A. Akpovo, L. Johnson, S. Pillai, S. Singh, Development of a LIBS assay for the detection of Salmonella enterica serovar Typhimurium from food, Anal. Bioanal. Chem. 400 (2011) 3323-3330. https://doi.org/10.1007/s00216-011-4844-3

[78] D.J. Malenfant, Influences on the Emissions of Bacterial Plasmas Generated through Nanosecond LaserInduced Breakdown Spectroscopy, University of Windsor, Windsor, 2016. https://scholar.uwindsor.ca/etd/5843

[79] M. Farid, S. Jeong, D. Seo, R. Ahmed, C. Lau, N. Gali, Z. Ning, A. An, Mechanistic insight into the in vitro toxicity of graphene oxide against biofilm forming bacteria using laser-induced breakdown spectroscopy, Nanoscale 10 (2018) 4475-4487. https://doi.org/10.1039/c8nr00189h

[80] W.A. Farooq, M. Atif, W. Tawfik, M.S. Alsalhi, Z.A. Alahmed, M. Sarfraz, J.P. Singh, Study of bacterial samples using laser-induced breakdown spectroscopy, Plasma Sci. Technol. 16 (2014) 1141-1146.

https://doi.org/10.1088/1009-0630/16/12/10

[81] H.L. Xu, G. Mejean, W. Liu, Y. Kamali, J.-F. Daigle, A. Azarm, P.T. Simard, P. Mathieu, G. Roy, J.-R. Simard, S.L. Chin, Remote detection of similar biological materials using femtosecond filament-induced breakdown spectroscopy, Appl. Phys. B 87 (2007) 151-156. https://doi.org/10.1007/s00340-006-2536-z 
[82] S.L. Chin, H.L. Xu, Q. Luo, F. Théberge, W. Liu, J.F. Daigle, Y. Kamali, P.T. Simard, J. Bernhardt, S.A. Hosseini, M. Sharifi, G. Méjean, A. Azarm, C. Marceau, O. Kosareva, V.P. Kandidov, N. Aközbek, A. Becker, G. Roy, P. Mathieu, J.R. Simard, M. Châteauneuf, J. Dubois, Filamentation "remote" sensing of chemical and biological agents/pollutants using only one femtosecond laser source, Appl. Phys. B 95 (2009) 1-12. https://doi.org/10.1007/s00340-009-3381-7

[83] K. Hamasha, Q.I. Mohaidat, R.A. Putnam, R.C. Woodman, S. Palchaudhuri, S.J. Rehse, Sensitive and specific discrimination of pathogenic and nonpathogenic Escherichia coli using Raman spectroscopy-a comparison of two multivariate analysis techniques, Biomed. Opt. Exp. 4 (2013) 481-489. https://doi.org/10.1364/BOE.4.000481 